\title{
Statistical Modeling of Brazilian In-Home PLC Channel Features
}

\author{
Thiago R. Oliveira, Antonio A. M. Picorone, Camila B. Zeller \\ Sergio L. Netto, Senior Member, IEEE, and Moises V. Ribeiro, Senior Member, IEEE
}

\begin{abstract}
This paper deals with the statistical modeling of key features of power line communication (PLC) channels that are necessary for designing data communication systems that operate over theses channels. The key features are average channel attenuation, root mean squared delay spread, coherence bandwidth and coherence time. All these features were estimated from in-home PLC channels measured in seven distinct Brazilian residences. Assuming that each feature is a random variable, four criteria (i.e., maximum likelihood estimate and three different information criteria) are used to select the statistical distribution that fits best to the data. The symmetry and asymmetry of the histogram associated with each feature is pointed out. The reported results focus on three frequency bands, namely: 1.7$30 \mathrm{MHz}, 1.7-50 \mathrm{MHz}$ and 1.7-100 MHz, which are in accordance with the standards used in Europe, North America and Brazil. The values obtained to Brazilian PLC channel features are different from those related to US and Europe channels reported in literature. Thus, the presented statistical models constitute an important tool to better design practical PLC systems that are suitable for Brazilian and in-home electric power grids.
\end{abstract}

Index Terms-power line communication, statistical modeling, data communication channel.

\section{INTRODUCTION}

$\mathbf{T}$ $\mathrm{HE}$ need for nurturing the technologies for Smart Grid (SG), Internet of Things (IoT) and Industry 4.0 demands the introduction of pervasive telecommunication systems and, as a consequence, the scarcity of spectrum may be alleviated by using all available medium for data communication purposes [1]-[3]. In this context, it is important to bring attention to power line communication (PLC) because it is a technology that makes use of the existing and ubiquitous infrastructure of electrical power systems to provide data communication.

The PLC has received considerable attention due to its low installation costs, as the electric power systems infrastructures are already available. Against the use of PLC technologies is the fact that electric power grids were not specified, designed and deployed for data communication purposes. In fact, power lines are electromagnetically unshielded and, as

T. R. Oliveira (thiago.oliveira@ifsudestemg.edu.br) is with the Electronics Department, Federal Institute of Education, Science and Technology of the Southeast of Minas Gerais (IFSEMG), Campus Juiz de Fora, Brazil.

Antonio A. M. Picorone (antonio.picorone@engenharia.ufjf.br) is with the Production Engineering and Mechanics Department, Federal University of Juiz de Fora (UFJF), Brazil.

Camila B. Zeller (camila.zeller@ufjf.edu.br) is with the Statistical Department, Federal University of Juiz de Fora (UFJF), Brazil.

S. L. Netto (sergioln@smt.ufrj.br) is with the Electrical Engineering Program at COPPE-Federal University of Rio de Janeiro (UFRJ), Brazil.

M. V. Ribeiro (mribeiro@engenharia.ufjf.r) is with the Electrical Engineering Department, Federal University of Juiz de Fora (UFJF), Brazil.

Digital Object Identifier: 10.14209/jcis.2019.16 a consequence, it interferes with and suffers interference from telecommunication systems operating in the same frequency band. Additionally, the transmitted signal is severely attenuated as frequency and/or distance increases, since the power lines are non-ideal conductors. Also, it is affected by high power impulsive noises due to loads dynamics and impedance mismatching frequently occurs due to the intrinsic topology of the electric distribution system. Overall, electric power grids represent a challenging data communication medium to be pursued but the necessity of data communication availability has continuously driven PLC technologies.

In its turn, the existence of telecommunication worldwide regulations imposes constraints on the widespread usage of PLC systems. In fact, these systems are considered as secondary users and sources of interference for primary users (e.g., telecommunication system operating in the same frequency band, such as military applications and amateur radio [4]-[7]). Therefore, the specification and design of PLC systems, which maximize the usage of available channel resources under the imposed constraints, requires a thorough study of the main features of electric power grids in the data communication perspective.

In this context, statistical models of some key features of PLC channels, which characterize the signal propagation influence of electric power grids over the transmitted signal, constitute an important and valuable information to be taken into account for the development and performance evaluation of PLC systems. Regarding wireless communication, Nakagami, Rician, Rayleigh and Weibull statistical distributions have been widely applied to model the fading behavior of wireless channels [8], [9]. More recently, the Gamma [10] and Inverse Gaussian [11] distributions were considered to model fading effects for frequencies above $60 \mathrm{GHz}$ in free-space optical communications. In PLC scenario, very few statistical analysis are available, with most of them addressing the PLC channels in US and European countries [12]-[17].

The main features of interest for statistical characterization of in-home PLC channels that are suitable for advancing the PLC systems are: average channel attenuation (ACA), root mean squared delay spread (RMS-DS), coherence bandwidth (CB), and coherence time (CT). The average channel gain in $\mathrm{dB}\left(\mathrm{ACG}_{\mathrm{dB}}\right)$ - the negative of $\mathrm{ACA}$ - and the RMS-DS, for in-home PLC channels, have their normality/log-normality discussed in a few papers on the related literature. In [16], for instance, measurements of PLC channels in US urban and suburban areas are presented with the frequency band 1.8$30 \mathrm{MHz}$. In [12], normality tests based on 60 PLC channels 
estimates, which were measured in six different homes, did not reject the null hypothesis in which $\mathrm{ACG}_{\mathrm{dB}}$ and RMS-DS were considered normally and log-normally distributed continuous variables, respectively. Also, [13] reported the analysis of 200 PLC channels estimates obtained in 25 different premises in Spain, with a frequency band $2-30 \mathrm{MHz}$. In that study, the normality assumption for $\mathrm{ACG}_{\mathrm{dB}}$ was rejected by all performed tests, whereas the log-normality assumption was validated for delay spread. In Italy, a set of 1,266 PLC channels was measured in the frequency band $1.8-100 \mathrm{MHz}$ [14]. The normality of $\mathrm{ACG}_{\mathrm{dB}}$ was not strictly confirmed, whereas the log-normality of RMS-DS was firmly advocated. Moreover, [15] discussed some results related to CB in Spanish in-home PLC channels for the frequency band 2-30 MHz. Regarding the frequencies up to $100 \mathrm{MHz}$, [18] and [14] discussed some CB results in France and Italy, respectively. The analyses related to the CT of PLC channels were addressed in few researches, such as [17], in which the CT estimates higher than $600 \mu$ s were obtained from the measured in-home PLC channels.

Even though the $\mathrm{CB}$ and $\mathrm{CT}$ are two of the main features for characterizing PLC channels, there is a clear lack of characterization for them in countries with distinct profiles from US and European countries. An attempt to overcome this problem is the analysis of ACA, RMS-DS, CB, and CT in Brazilian in-home PLC channels provided in [19]. Also, an initial attempt to provide statistical modelings of ACG and delay spread in Brazil was introduced in [20].

Aiming to provide a better understanding about Brazilian electric power grids usability for data communication purposes, this work focuses on a comprehensive discussion of statistical modeling of key features of Brazilian in-home PLC channels, covering three important frequency bands. In this regard, the main contributions of this paper are the following:

- Statistical models are provided for the ACA, RMSDS, CB, and CT parameters, which were obtained from several PLC-channel estimates from seven typical and different homes in Brazilian urban area.

- The data sets constituted by all measured features are submitted to a modeling procedure that evaluated the suitability of several continuous statistical distributions, of up to three parameters, including symmetric (Logistic, Normal and t-Student) and asymmetric (Exponential, Gamma, Inverse Gaussian, Log-logistic, Log-normal, Nakagami, Rayleigh, Rician, Skew-normal and Weibull) ones.

- The choice of the best statistical distribution is based on the log-likelihood function and three distinct information criteria, namely Akaike information criterion (AIC), Bayesian information criterion (BIC), and efficient determination criterion (EDC) [21].

- The analysis comprises three distinct frequency bands: Band A (1.7-30 MHz), Band B (1.7-50 MHz) and Band C (1.7-100 MHz). Note that Band A applies to some European countries [22], Band B refers to the regulation imposed by Brazilian telecommunication regulatory authority [23], and Band C covers future PLC systems offering data rates in order of 1-2 Gbps [16].
Through the development of this study, the following statements regarding the statistical modelings of Brazilian in-home PLC channels features can be determined:

- The ACA feature is better fitted by the Skew-normal distribution in Band A and by the Nakagami distribution in Bands B and C.

- The RMS-DS is better fitted in all frequency bands by Gamma distribution, while the Log-normal distribution offers quite similar fitting results.

- The best fit for CB is provided by the Inverse Gaussian distribution in Bands $\mathrm{A}$ and $\mathrm{C}$, while the Log-logistic distribution is the best one for Band B. Moreover, the Skew-normal distribution yields the best fits for CT in all frequency bands. It is important to emphasize that the statistical analysis of $\mathrm{CB}$ and $\mathrm{CT}$ constitutes the first attempt to statistically model these important PLC channel features.

The remainder of this paper is organized as follows: Section II addresses the PLC channel measurement setup and campaign. Section III defines the PLC channel features of interest: ACA, RMS-DS, CB and CT. Section IV deals with the formal concepts behind the maximum likelihood estimation process. Section $\mathrm{V}$ presents and discusses the modeling results for the ACA, RMS-DS, CB and CT features, including comparisons with other results found in the related literature. Finally, Section VI closes the paper summarizing its main findings.

\section{Measurement Setup and Campaign}

The statistical characterization and modeling of the most important PLC-channel features were supported by estimates of channel frequency responses (CFRs), which were obtained from a measurement campaign in seven Brazilian in-home facilities. The block diagram of the PLC CFR measurement setup is shown in Fig. 1, which consists of the following three main components [24]:

- Signal generator: Equipment composed of an arbitrary signal generator board mounted in a rugged computer. A pre-designed sounding sequence is loaded into it and converted to an analog signal, which is used to estimate the PLC CFRs. Essentially, the sounding sequence is composed of consecutive Hermitian symmetric orthogonal frequency division multiplexing (HS-OFDM) [25] symbols with $2 N$ subcarriers and a cyclic prefix of length $L_{c p}$.

- Data digitizer: Equipment composed of a data acquisition board mounted in a rugged computer. It is responsible for collecting the sounding signal that was distorted by the propagation effects associated with the electric power grids.

- Coupler: Circuitry used to connect both signal generator and data digitizer to the electric power grids under analysis [26]. The designed coupler introduces an insertion loss lower than $2 \mathrm{~dB}$ in the frequency band $1.7-100 \mathrm{MHz}$.

The PLC CFR estimates are obtained through the channelestimation methodology applied in both transmitted (from the signal generator) and received (by the data digitizer) sounding 


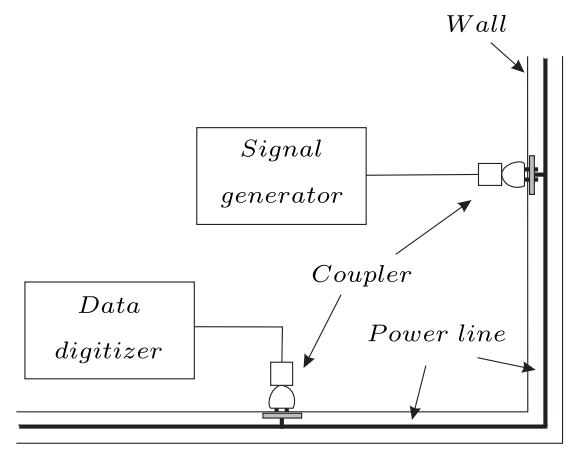

Fig. 1: The block diagram of the measurement setup.

signals, as detailed in [24], [27], [28]. The adopted parameters in the channel-estimation methodology are summarized in Table I. By adopting a sampling frequency of $200 \mathrm{MHz}$, the resulting frequency resolution is around $48.83 \mathrm{kHz}$. From the values chosen for $N$ and $L_{c p}$ chosen values, the CFR estimates are obtained every $23.04 \mu \mathrm{s}$ (which is the time interval duration of the HS-OFDM symbol), approximately. Note that the adopted time interval duration is much shorter than the minimum value of CT of $600 \mu \mathrm{s}$, as desired, which was found in in-home Spanish facilities, covering the frequency band of 1.7-30 MHz [17].

TABLE I: Main configuration parameters adopted for estimating the PLC CFRs [24].

\begin{tabular}{c|c}
\hline \hline Description & Value \\
\hline \hline Sampling frequency & $f_{s}=200 \mathrm{MHz}$ \\
\hline Number of sub-carriers & $N=2048$ \\
\hline Modulation & BPSK \\
\hline Cyclic prefix length & $L_{c p}=512$ \\
\hline Frequency resolution & $\Delta_{f}=48.83 \mathrm{kHz}$ \\
\hline Symbol duration & $23.04 \mu \mathrm{s}$ \\
\hline \hline
\end{tabular}

A measurement campaign was carried out in seven distinct and typical sites (residences) in an urban area in Brazil, as described in Table II. In the entire measurement campaign, 245 different outlet pairs (i.e., electric circuits) were measured, providing a total of 148,037 CFR estimates, with an average of 604 consecutive CFR estimates for each outlet pair.

TABLE II: Main characteristics of the measured places.

\begin{tabular}{c|c|c}
\hline \hline Construction type & Age (years) & Constructed area $\left(\mathrm{m}^{2}\right)$ \\
\hline \hline House \#1 & 30 & 78 \\
\hline House \#2 & 10 & 69 \\
\hline Apartment \#1 & 9 & 54 \\
\hline Apartment \#2 & 9 & 42 \\
\hline Apartment \#3 & 18 & 65 \\
\hline Apartment \#4 & 3 & 62 \\
\hline Apartment \#5 & 2 & 54 \\
\hline
\end{tabular}

\section{Power Line Features Under Investigation}

This section defines the ACA, RMS-DS, CB, and CT features. In this context, we assume that the PLC channel is modeled as band limited, linear and time invariant system, as the time interval duration of each HS-OFDM symbol is much shorter than the coherence time. From now on, the channel impulse response of a PLC channel is denoted by $h(t) \in \mathbb{R} \mid t \in\left[0, T_{h}\right)$, and its corresponding Fourier transform is represented by $H(f) \in \mathbb{C} \mid-B<f<B$, in which $B$ is the considered frequency bandwidth.

\section{A. Average channel attenuation}

The average channel gain (ACG) is given by

$$
\mathrm{ACG}_{\mathrm{dB}}=10 \log _{10}\left(\frac{1}{2 B} \int_{-B}^{B}|H(f)|^{2} d f\right) .
$$

As some of statistical distributions considered in this study can not assume negative values, we opt to analyze the ACA feature defined as $\mathrm{ACA}=-\mathrm{ACG}_{\mathrm{dB}}$.

\section{B. Root mean squared delay spread}

The RMS-DS denotes the distribution of transmitted power over several paths in a multipath environment. It can be defined as the square root of second central moment of a power delay profile, as given by

$$
\tau_{r m s}=\sqrt{\frac{\int_{0}^{\infty}(\tau-\bar{\tau})^{2} h^{2}(\tau) d \tau}{\int_{0}^{\infty} h^{2}(\tau) d \tau}},
$$

where

$$
\bar{\tau}=\frac{\int_{\tau_{\min }}^{\tau_{\max }} \tau h^{2}(\tau) d \tau}{\int_{\tau_{\min }}^{\tau_{\max }} h^{2}(\tau) d \tau},
$$

$\tau_{\min }$ and $\tau_{\max }$ are the arrival times of the first and last paths, respectively. Such channel feature indicates how disperse the communication channel is. This information is usually used to support the specification of the guard or cyclic-prefix interval duration in a multi-carrier modulation (e.g., HS-OFDM and OFDM) to avoid inter-symbol interference.

\section{Coherence bandwidth}

The CB parameter reflects the CFR selectivity, and it can be obtained by using the correlation function given by

$$
R\left(\Delta_{f}\right)=\int H(f) H^{*}\left(f+\Delta_{f}\right) d f,
$$

in which $\Delta_{f} \in \mathbb{R}_{+}$denotes the frequency spacing and $\left\{{ }^{*}\right\}$ is the conjugate operator. The value of coherence bandwidth $\left(B_{c}\right)$ is determined from the relationship

$$
\left|R\left(B_{c}\right)\right|=\gamma|R(0)|,
$$

where $\gamma \in \mathbb{R} \mid 0<\gamma<1$ is the correlation level indicating that the channel frequency response does not vary considerable when $\Delta_{f} \in\left[0, B_{c}\right]$. Based on the use of HS-OFDM scheme and the values in Table I, in our study we get $B_{c}=(B / N) \lambda \approx$ $48.83 \lambda \mathrm{kHz}$, where $\lambda=0,1, \ldots, N-1$. From its definition, the $\mathrm{CB}$ is a key parameter to evaluate the need for equalization in a practical data communication scheme. 


\section{Coherence Time}

The CT is the time duration in which the PLC-channel impulse response can be considered time invariant. By assuming that the PLC channel is a wide-sense stationary uncorrelated scattering (WSSUS) process [29], the CT feature becomes related to the coherence time of the complex gains, $\alpha_{l}(t)$, which incorporate both attenuation and phase deviations due to $l=1,2, \ldots, L$ signal multiple reflections in the communication medium.

In its turn, the coherence index between samples of $\alpha_{l}(t)$, taken $\Delta t$ time units apart, is given by

$$
\rho_{\alpha_{l}}=\frac{E\left[\alpha_{l}(t) \alpha_{l}^{*}(t+\Delta t)\right]}{E\left[\left|\alpha_{l}^{2}(t)\right|\right]},
$$

in which $E[$.$] is the expectation operator. Thus, it can be$ assumed that the correlation index of the PLC channel is given by

$$
\rho_{h}(\Delta t)=\frac{\sum_{l=1}^{L} P_{l} \rho_{\alpha_{l}}(\Delta t)}{\sum_{l=1}^{L} P_{l}} ; 0 \leq\left|\rho_{h}(\Delta t)\right| \leq 1,
$$

where $P_{l}=E\left[\left|\alpha_{l}^{2}(t)\right|\right]$ is the average power of the $l^{\text {th }}$ path. Hence, the $\mathrm{CT}$ feature can be obtained through the relationship

$$
\left|\rho_{h}\left(T_{c}^{\beta}\right)\right| \geq \beta,
$$

where $0<\beta<1$ refers to the minimum correlation index admitted to characterize the channel as time-invariant during the time interval $\Delta t=T_{c}^{\beta}$. For a HS-OFDM based scheme, the CT for the correlation index $\beta$, denoted by $T_{c}^{\beta}$, can be estimated by using [29]

$$
T_{c}^{\beta}=M_{c}\left(2 N+L_{c p}\right) T_{s},
$$

where $T_{s}=1 / f_{s}$ denotes the sampling period, $2 N$ is the number of subcarriers, $L_{c p}$ is the length of the cyclic prefix in the HS-OFDM symbol, and $M_{c}$ is the number of consecutive channel estimates required to reach a correlation score equal to $0<\beta<1$. In other words, $M_{c}$ is the number of consecutive channel estimates in which a correlation of $\beta$ between them, can be observed. In this sense, the higher is the value of $M_{c}$, the longer will be the coherence time.

In practice, the CT feature is crucial for instance to inform the periodicity of channel state information that must be provided for performing channel equalization and resource allocation.

\section{Statistical Modeling Evaluation}

Assuming that the features are random variables, than the fitting between their data sets and any statistical distribution may be evaluated in terms of different criteria, as described below.

\section{A. Maximum Likelihood Estimate}

Let $X=x_{i}$ denotes a realization of a random variable with a parametric probability density function (pdf) $f(x \mid \boldsymbol{\theta})$, where $\boldsymbol{\theta}=\left[\theta_{1}, \ldots, \theta_{K}\right]^{T}$ denotes $K$ unknown parameters. Thus, the likelihood function can be expressed as [30]

$$
L(\boldsymbol{\theta})=\prod_{i} f\left(x_{i} \mid \theta_{1}, \ldots, \theta_{K}\right)
$$

which is commonly replaced by its logarithmic version, referred as log-likelihood, which is given by

$$
\gamma(\boldsymbol{\theta})=\sum_{i} \log \left(f\left(x_{i} \mid \theta_{1}, \ldots, \theta_{K}\right)\right) .
$$

The maximum likelihood estimate (MLE), represented by vector $\hat{\boldsymbol{\theta}}$, is obtained by

$$
\hat{\boldsymbol{\theta}}=\arg \max _{\boldsymbol{\theta}} \gamma(\boldsymbol{\theta}) .
$$

Such maximization problem is easily performed for some distributions with analytic solutions, as it occurs, for instance, for Normal distribution. On the other hand, analytic solution for others statistical distributions (e.g., Skew-normal and Gamma distributions) can be very complicated and, as a consequence, numerical procedures may apply [31].

\section{B. The information Criteria}

These criteria quantitatively evaluate the suitability of a statistical distribution to model a data set by penalizing the number of parameters in each distribution to avoid data overfitting. The three information criteria considered here, namely the Akaike information criterion (AIC), Bayesian information criterion (BIC), and efficient determination criterion (EDC), have the general form of [21]

$$
-2 \gamma(\hat{\boldsymbol{\theta}})+K c_{n},
$$

where $K$ is the number of parameters used by a pdf and $c_{n}$ is the penalty term of the criterion. Note that $c_{n}$ is in accordance with Table III, where $n$ denotes the data set size. Different from the log-likelihood function, a low value of the information criterion means a better fitting between data set and the statistical distribution.

TABLE III: Penalty term $c_{n}$ of the information criteria.

\begin{tabular}{c|c}
\hline \hline Criterion & $c_{n}$ \\
\hline AIC & 2 \\
\hline BIC & $\log (n)$ \\
\hline EDC & $0.2 \sqrt{n}$ \\
\hline
\end{tabular}

\section{Numerical Results}

Statistical analyses were performed in the data sets of the ACA, RMS-DS, CB, and CT features, extracted from the measured in-home PLC channels covering the following three frequency bands:

- Band A: 1.7-30 MHz.

- Band B: 1.7-50 MHz.

- Band C: 1.7-100 MHz.

The statistical modeling was based on several symmetric and asymmetric continuous statistical distributions, which were chosen according to the general behavior observed in each data set. In this sense, the chosen symmetric distributions are the Logistic, Normal, and t-Student, while the asymmetric ones are the Exponential, Gamma, Inverse Gaussian, Log-logistic, Log-normal, Nakagami, Rayleigh, Rician, Skewnormal, and Weibull. The statistical analysis of each feature is presented in the following subsections. 


\section{A. ACA Statistical Analysis}

The parameters of all considered statistical distributions, applied to fit the ACA, are listed in Tables IV-VI, for Bands $\mathrm{A}, \mathrm{B}$ and $\mathrm{C}$, respectively. The statistical models that best fit the ACA, the fit to the normal distribution and the histograms of the dataset that represents the ACA can be observed in Fig. 2. From these results, one can note that the Skew-normal distribution offers the best fit to the ACA values obtained from the measured Brazilian in-home PLC channels, when considering Band A. Moreover, the Nakagami distribution achieves the best fits for Bands B and C. At this point, it is important to emphasize that the fitting is performed in the datasets instead of the histograms that represent them, since the format of the histograms are due to the dataset but is strongly dependent to the chosen number of bins. Thus, the quality of the achieved fit is not verified only by the inspection of the corresponding histogram, but together with the analysis of the achieved MLE score. The above comment is also applied to all considered channel parameters.

Regarding Band A and based on some normality tests, the ACA was considered normally distributed in some US in-home PLC channels, as detailed in [16]. The mean values for ACA in US is more than two times the one observed in Brazilian residences and this difference is probably related to the fact that the sizes of typical apartments and residences in Brazil are smaller than in US (see Table II in [12]). These same tests were performed in in-home PLC channels in Spain [13], and the null hypothesis in which ACA is considered normally distributed was rejected. In that contribution, the Jarque-Bera, Lilliefors, and Kolmogorov-Smirnov tests [32], performed at 5\% and 1\% correlation levels, were applied and normality assumption with respect to ACA feature was also strongly rejected. The values of ACA reported from Spain are close to those encountered in US. Regarding the measured Brazilan PLC channels, the use of the Normal distribution seems to be not appropriate to give a reasonable model for the ACA. This is because among the tested distributions, the normal is just the eighth best fit, for Band A. On the other hand, the normal distribution can be eventually used in Bands B and C, although it is the fourth best fit, but the MLE score is quite close when comparing the normal and the first three best statistical models, as can be observed in Tables V and VI, for Bands B and C, respectively.

Regarding Band C, for comparison purposes, [14] showed that the Normal distribution yields the best fit to ACA values related to Italian in-home PLC channels. In that paper, the mean and standard deviation associated with the Normal distribution, $(\mu, \sigma)$, are equal to $(35.412,10.521) \mathrm{dB}$, where the values $(30.211,9.158) \mathrm{dB}$ are obtained in the Brazilian in-home scenario. These results reinforce the fact that Italian in-home PLC channels faces more attenuation, around $5 \mathrm{~dB}$, in comparison to their Brazilian counterparts.

\section{B. RMS-DS Statistical Analysis}

With respect to the statistical modeling of the RMS-DS feature, the histograms depicted in Fig. 3 show a clear positive asymmetry. In fact, the analysis of RMS-DS for Brazilian in-home PLC channels revealed that this feature is better

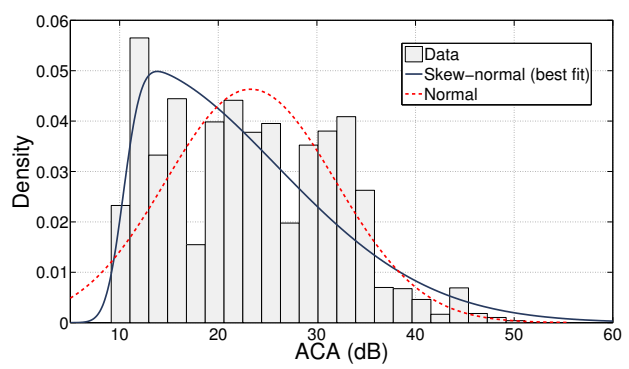

(a) ACA for Band A.

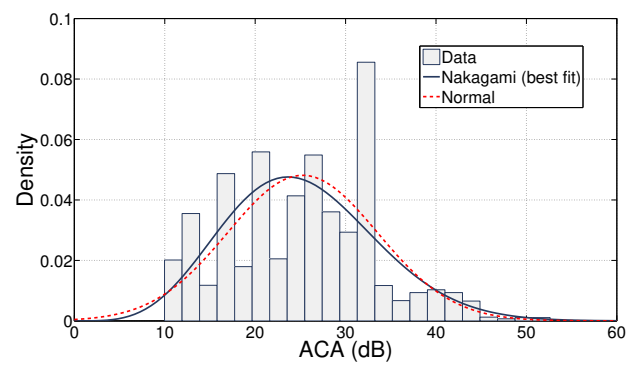

(b) ACA for Band B.

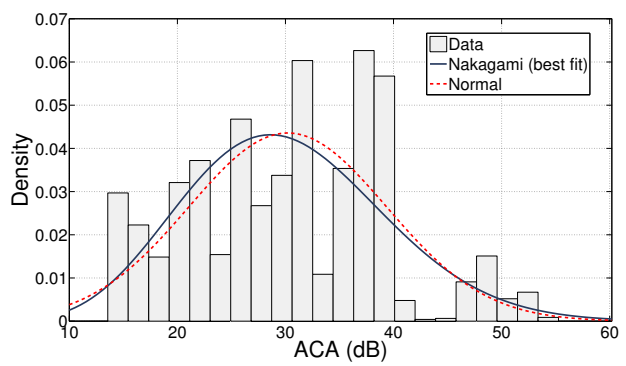

(c) ACA for Band C.

Fig. 2: The histograms and the best distribution for the ACA feature. The Normal distribution is included for comparison purpose.

modeled by a Gamma distribution, for all three frequency bands considered here. This result is different from those reported for in-home PLC channels in US [16], [22] and for in-home PLC channels in Spain [13], regarding frequency Band A. Also, it differs from the one presented in [14] for Italian in-home PLC channels in Band C, in which RMS-DS was considered to be log-normally distributed. Furthermore, the values of RMS-DS observed in US and Europe are higher than those estimated from Brazilian power lines. This matches the same observation applied to justify the discrepancy verified in ACA parameter from different countries, due to the size of the measured residences, in which are probably smaller in Brazil.

On the other hand, the obtained results with the Normal distribution applied to the RMS-DS values extracted from the Brazilian in-home PLC channels are not so distant to those obtained with the Gamma distribution, as give in Tables VIIIX. For instance, regarding Band $\mathrm{A}$, a very low relative difference of 0.02 is observed between the EDC values for Gamma and Log-normal distributions. The suitability of the Log-normal distribution to fit the RMS-DS can be visualized 


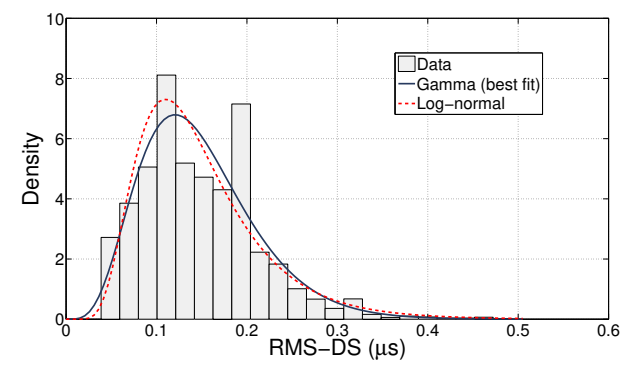

(a) RMS-DS for Band A.

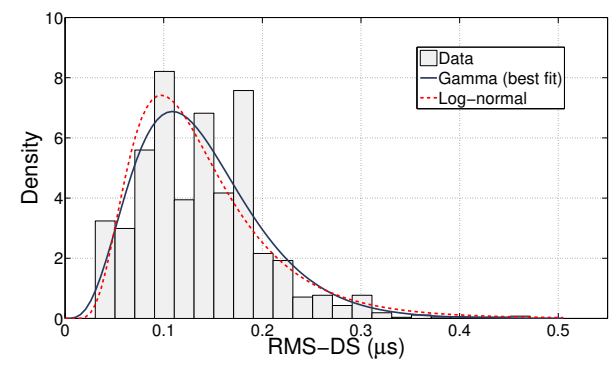

(b) RMS-DS for Band B.

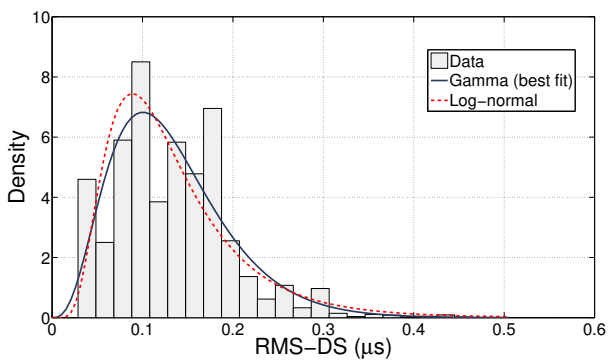

(c) RMS-DS for Band C.

Fig. 3: The histograms and the best distribution for the RMS-DS feature. The Log-normal distribution is included for comparison purpose.

in Fig. 3a. Similar behavior is observed for both Band B and Band C, as depicted in Figs. 3b and 3c, respectively.

\section{CB Statistical Analysis}

The CB values estimated from the measured in-home PLC channels are analyzed in this contribution with respect to a correlation level of $90 \%$. Comparing the CB values (at a $90 \%$ of correlation level) extracted from Brazilian in-home PLC channels with their Spanish [15] (for Band A) and French [18] (for Band C) counterparts, larger CB values can be observed in the Brazilian PLC channels. In fact, the maximum CB value in Brazil is almost $3 \mathrm{MHz}$, approximately 1.6 and 2.5 times its French and Spanish counterparts, respectively.

The statistical modeling of the CB feature revealed that it is better fitted by the Inverse Gaussian distribution for Band A and Band C, as shown in Figs. 4a and 4c, respectively. For Band B, the best fit is achieved by the Log-logistic distribution. For comparison purposes, the fit for the Log-normal distribution is also depicted in Fig. 4, since the histograms suggest that the $\mathrm{CB}$ data set presents positive asymmetry. It is important

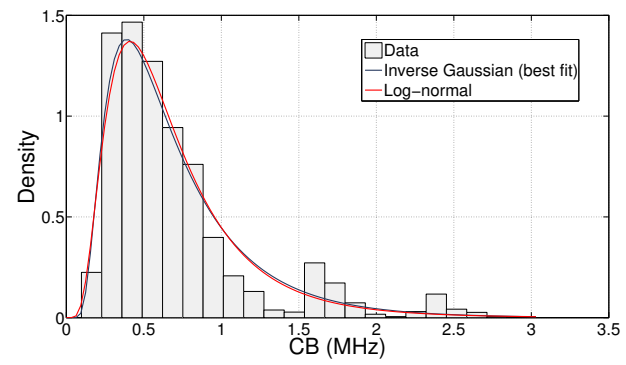

(a) $\mathrm{CB}$ for Band $\mathrm{A}$.

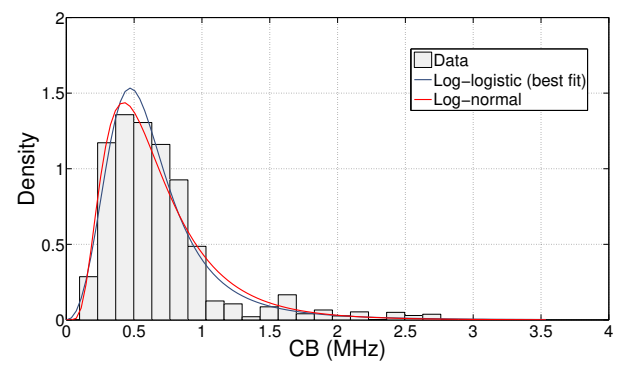

(b) $\mathrm{CB}$ for Band $\mathrm{B}$.

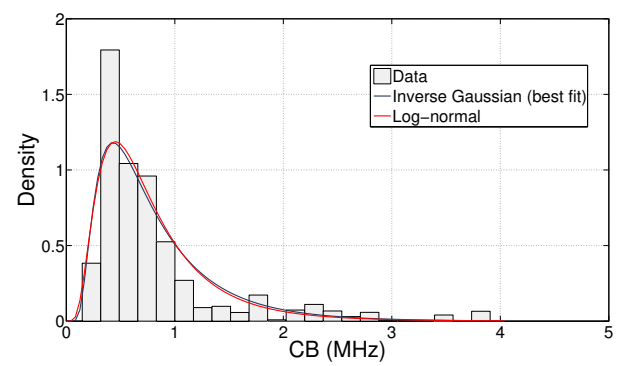

(c) $\mathrm{CB}$ for Band $\mathrm{C}$.

Fig. 4: The histograms and the best distribution for the CB feature. The Log-normal distribution is included for comparison purpose.

to state that the fit offered by the Log-normal distribution yields very close performance to the distributions offering the best fits in terms of log-likelihood and all evaluated criteria, something that is much more accentuated in Bands A and C. The parameters for each considered statistical distribution, including the Log-normal one, together with all criterion values are listed in Tables X-XII, for Bands A, B and C, respectively.

Since the statistical modeling of CB values, to the authors' best knowledge, is firstly introduced in this contribution, no comparison can be performed against previous related papers.

\section{CT Statistical Analysis}

The CT data set is constituted by less samples in comparison with the ACA, RMS-DS, and CB data sets, due to the methodology applied to estimate this feature. In fact, the CT values are derived from a set of consecutive CFRs, and only those combinations that rendered more than 640 consecutive CFR estimates where considered. This means that the data set for CT values is composed of only 178 estimates. 
For this feature, the histograms depicted in Fig. 5 show some negative asymmetry of the CT values. This observation is reinforced by the fact that the Skew-normal is the best statistical distribution, with a negative skewness, as indicated by the value of $\gamma$ in Tables XIII-XV for all considered frequency bands. As can be observed, the second-best statistical distribution provides fitting scores far worst than those achieved by the best distribution in each band, and, as a consequence, they may not be chosen to model the CT associated with the Brazilian in-home PLC channels.

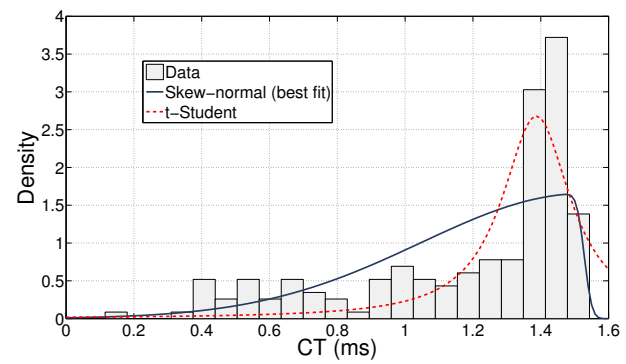

(a) CT for Band A.

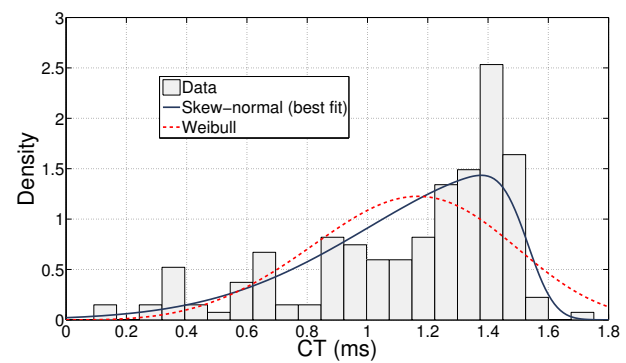

(b) CT for Band B

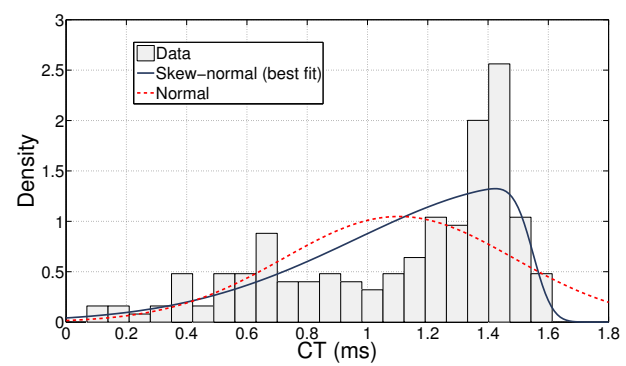

(c) CT for Band C.

Fig. 5: The histograms and the best distributions for the CT feature.

\section{CONCLUSION}

This paper have provided statistical models of key features of in-home PLC channels. The average channel attenuation, root mean squared delay spread, coherence bandwidth and coherence time features were obtained from PLC-channel estimates yielded by a measurement campaign carried out in a Brazilian urban area. The covered frequency bands were 1.7$30 \mathrm{MHz}$ (Band A), 1.7-50 MHz (Band B), and 1.7-100 MHz (Band C).
The attained results have shown that the average channel attenuation feature is better fitted by the Skew-normal distribution in Band A, and by the Nakagami distribution in Bands B and $\mathrm{C}$. The root mean squared delay spread feature is better fitted in all frequency bands by the Gamma distribution, having the Log-normal distribution achieving very similar modeling results. Regarding the coherence bandwidth feature, the best fit was obtained with the Inverse Gaussian distribution for Bands A and C, while the Log-logistic distribution offered the best fit for Band B. Finally, the Skew-normal distribution yields the best fits for the coherence time feature in all frequency bands.

Comparisons with previous studies carried out in US and Europe (Spain, France, and Italy) have shown the existing similarities and, most importantly, differences from Brazilian PLC channels. For instance, the normality assumption for the average channel attenuation verified in some countries may not be accepted in the Brazilian case. On the other hand, the lognormality of the root mean squared delay spread was verified in several countries, including Brazil.

Indeed, the provided models are more suitable to represent Brazilian PLC channels and thus, they are useful for developing data communication systems which are capable of maximizing the use of available resources in Brazilian electric power grids.

\section{ACKNOWLEDGMENT}

This study was financed in part by the Coordenação de Aperfeiçoamento de Pessoal de Nível Superior - Brasil (CAPES) - Finance Code 001, FINEP, FAPEMIG, CNPq, INERGE, and Smarti9 LTD.

\section{REFERENCES}

[1] S. Galli, A. Scaglione, and Z. Wang, "For the grid and through the grid: The role of power line communications in the smart grid," Proceedings of the IEEE, vol. 99, no. 6, pp. 998-1027, June 2011, doi: 10.1109/JPROC.2011.2109670.

[2] R. Struzak, T. Tjelta, and J. P. Borrego, "On radio-frequency spectrum management," URSI Radio Science Bulletin, vol. 2015, no. 354, pp. 1135, Sept. 2015, doi: 10.1109/AFRCON.1996.563130.

[3] L. de M. B. A. Dib, V. Fernandes, M. de L. Filomeno, and M. V. Ribeiro, "Hybrid PLC/wireless communication for smart grids and Internet of things applications," IEEE Internet of Things Journal, vol. 5, no. 2, pp. 655-667, Apr. 2018, doi: 10.1109/JIOT.2017.2764747.

[4] M. Gebhardt, F. Weinmann, and K. Dostert, "Physical and regulatory constraints for communication over the power supply grid," IEEE Communications Magazine, vol. 41, no. 5, pp. 84-90, May 2003, doi: 10.1109/MCOM.2003.1200106.

[5] IEC 610003-8, "Electromagnectic Compatibility (EMC) - Part 3: Limits - Section 8: Signaling on Low-Voltage Electrical Installations - Emission Levels, Frequency Bands and Electromagnectic Disturbances Levels", Geneva, Switzerland, 2002.

[6] FCC, "Code of Federal Regulations - Title 47: Telecommunication Chapter I: FCC Part 15 - Radio Frequency Devices", Washington, DC, 2002.

[7] CISPR 22, "Information Technology Equipment - Radio Disturbance Characteristics - Limits and Methods of Measurement", Geneva, Switzerland, 2002.

[8] M. K. Simon and M. S. Alouini, Digital Communication Over Fading Channels, John Wiley \& Sons, 2000, doi: 10.1002/0471200697.

[9] D. C. Pavlovic, N. M. Sekulovic, G. V. Milovanovic, A. S. Panajotovic, M. C. Stefanovic, and Z. J. Popovic, "Statistics for ratios of Rayleigh, Rician, Nakagami-m, and Weibull distributed random variables," Mathematical Problems in Engineering, vol. 2013, 2013, doi: $10.1155 / 2013 / 252804$. 
[10] P. M. Shankar, "Performance analysis of diversity combining algorithms in shadowed fading channels," Wireless Personal Communications, vol. 37, no. 1-2, pp. 61-72, 2006, doi: 10.1007/s11277-006-1080-9.

[11] I. Trigui, A. Laourine, S. Affes, and A. Stephenne, "The inverse Gaussian distribution in wireless channels: Second-order statistics and channel capacity," IEEE Transactions on Communications, vol. 60, no. 11, pp. 3167-3173, Nov. 2012, doi: 10.1109/TCOMM.2012.081512.100253.

[12] B. O'Mahony, "Field testing of high-speed power line communications in North American homes," in Proc. IEEE International Symposium on Power Line Communications and Its Applications, 2006, doi: 10.1109/ISPLC.2006.247453, pp. 155-159.

[13] J. A. Cortes, F. J. Canete, L. Díez, and J. L. G. Moreno, "On the statistical properties of indoor power line channels: Measurements and models," in Proc. IEEE International Symposium on Power Line Communications and Its Applications, Apr. 2011, doi: 10.1109/ISPLC.2011.5764406, pp. 271-276.

[14] A. M. Tonello, F. Versolatto, and A. Pittolo, "In-home power line communication channel: Statistical characterization," IEEE Trans. on Communications, vol. 62, no. 6, pp. 2096-2106, June 2014, doi: 10.1109/TCOMM.2014.2317790.

[15] F. J. Canete, J. A. Cortés, L. Díez, and J. T. Entrambasaguas, "A channel model proposal for indoor power line communications," IEEE Communications Magazine, vol. 49, no. 12, pp. 166-174, Dec. 2011 doi: 10.1109/MCOM.2011.6094022.

[16] S. Galli and T. Banwell, "A novel approach to the modeling of the indoor power line channel-part II: Transfer function and its properties," IEEE Transactions on Power Delivery, vol. 20, no. 3, pp. 1869-1878, July 2005, doi: 10.1109/TPWRD.2005.848732.

[17] F. Corripio, J. Arrabal, L. del Rio, and J. Munoz, "Analysis of the cyclic short-term variation of indoor power line channels," IEEE Journal on Selected Areas in Communications, vol. 24, no. 7, pp. 1327-1338, July 2006, doi: 10.1109/JSAC.2006.874402.

[18] M. Tlich, A. Zeddam, F. Moulin, and F. Gauthier, "Indoor power-line communications channel characterization up to $100 \mathrm{MHz}$ - Part II: Timefrequency analysis," IEEE Transactions on Power Delivery, vol. 23, no. 3, pp. 1402-1409, July 2008, doi: 10.1109/TPWRD.2007.916095.

[19] T. R. Oliveira, A. A. Picorone, S. L. Netto, and M. V. Ribeiro, "Characterization of Brazilian in-home power line channels for data communication," Electric Power Systems Research, vol. 150, no. Supplement C, pp. 188 - 197, 2017, doi: 10.1016/j.epsr.2017.05.011.

[20] T. R. Oliveira, C. B. Zeller, S. L. Netto, and M. V. Ribeiro, "Statistical modeling of the average channel gain and delay spread in in-home PLC channels," in Proc. in IEEE International Symposium on Power Line Communications and Its Applications, Mar. 2015, doi: 10.1109/ISPLC.2015.7147611, pp. 184-188

[21] C. R. B. Cabral, V. H. Lachos, and C. B. Zeller, "Multivariate measurement error models using finite mixtures of skew-Student t distributions," Journal of Multivariate Analysis, vol. 124, no. C, pp. 179-198, 2014, doi: 10.1016/j.jmva.2013.10.017.

[22] S. Galli, "A novel approach to the statistical modeling of wireline channels," IEEE Transactions on Communications, vol. 59, no. 5, pp. 1332-1345, May 2011, doi: 10.1109/TCOMM.2011.031611.090692.

[23] Brazilian Regulation for Broadband PLC (in Portuguese), National Agency of Telecommunications (ANATEL), http://legislacao.anatel.gov.br/resolucoes/2009/101-resolucao-527, Dec. 2014.

[24] T. R. Oliveira, C. A. G. Marques, W. A. Finamore, S. L. Netto, and M. V. Ribeiro, "A methodology for estimating frequency responses of electric power grids," Journal of Control, Automation and Electrical Systems, vol. 25, no. 6, pp. 720-731, 2014, doi: 10.1007/s40313-014-0151-5.

[25] M. V. Ribeiro, G. R. Colen, F. V. P. de Campos, Z. Quan, and H. V. Poor, "Clustered-orthogonal frequency division multiplexing for power line communication: When is it beneficial?" IET Communications, vol. 8, no. 13, pp. 2336-2347, Sept. 2014, doi: 10.1049/iet-com.2014.0056.

[26] L. G. da Silva Costa, A. C. M. de Queiroz, B. Adebisi, V. L. R. da Costa, and M. V. Ribeiro, "Coupling for power line communications: A survey," Journal of Communication and Information Systems, vol. 32, no. 1, 2017, doi: 10.1109/ISPLC.2007.371 179

[27] J. Parsons, D. Demery, and A. Turkmani, "Sounding techniques for wideband mobile radio channels: A review," IEEE Proceedings in Communications, Speech and Vision, vol. 138, no. 5, pp. 437-446, Oct. 1991, doi: 10.1049/ip-i-2.1991.0059.

[28] T. R. Oliveira, W. A. Finamore, and M. V. Ribeiro, "A sounding method based on OFDM modulation for PLC channel measurement," in Proc. IEEE International Symposium on Power Line Communications and Its Applications, Mar. 2013, doi: 10.1109/ISPLC.2013.6525847, pp. 185190.
[29] A. A. M. Picorone, R. Sampaio-Neto, and M. V. Ribeiro, "Coherence time and sparsity of Brazilian outdoor PLC channels: A preliminary analysis," in Proc. IEEE International Symposium on Power Line Communications and Its Applications, Glasgow, United Kingdom, Mar. 2014, doi: 10.1109/ISPLC.2014.6812337, pp. 1-5.

[30] A. M. Mood, F. A. Graybill, and D. C. Boes, Introduction to the Theory of Statistics, 3rd ed., McGraw Hill, 1974.

[31] G. Casella and R. L. Berger, Statistical Inference, Duxbury, 2002.

[32] J. H. Zar, Biostatistical Analysis, Pearson, 2010.

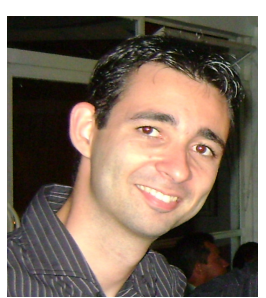

Thiago Rodrigues Oliveira received the B.S. (2007), M.Sc. (2010) and D.Sc. (2015) degrees from Federal University of Juiz de Fora (UFJF), all in Electrical Engineering. He has been an Associate Professor at the Department of Electronics of the Federal Institute of Education, Science and Technology of the Southeast of Minas Gerais, Juiz de Fora, Brazil. His currently research works involve the following topics: digital signal processing, digital communication, internet of things, power line medium characterization.

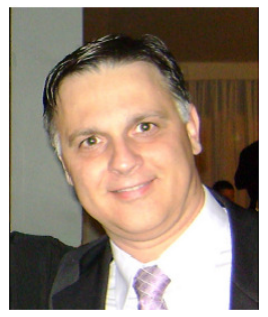

Antonio A. M. Picorone was born in So Joo Nepomuceno - MG, Brazil, in 1967. He has a Licentiate in Science (1999) and postgraduate in Mathematics (2002) at Centro de Ensino Superior de Juiz de Fora (CES/JF), Juiz de Fora - MG (Brazil). He received B.Sc. (2007), M.Sc. (2009) and D.Sc. (2014) in Electrical Engineering from the Federal University of Juiz de Fora (UFJF), Brazil. He worked for 28 years with telecommunications infrastructure at Companhia Energtica de Minas Gerais (CEMIG). Since 2017, he has been an Associate Professor at the Production and Mechanical Engineering Department at UFJF. His research interests include digital communications, PLC channel modeling and estimation, smart grids, internet of things, industry 4.0 and smart city.

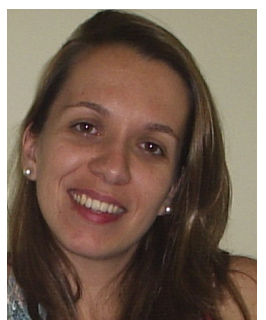

Camila Borelli Zeller is a Professor in the Department of Statistics at the Federal University of Juiz de Fora, Brazil. She holds a Masters degree (2006) and a PhD (2009) in Statistics, from the University of Campinas, Brazil. The main focus of her research is asymmetric distributions, linear models and finite mixtures of distributions. 


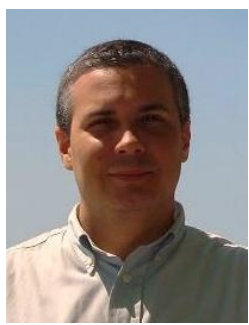

Sergio L. Netto was born in Rio de Janeiro, Brazil. He received the B.Sc. degree (cum laude) from the Federal University of Rio de Janeiro (UFRJ), Brazil, in 1991, the M.Sc. degree from COPPE/UFRJ in 1992, and the Ph.D. degree from the University of Victoria, BC, Canada, in 1996, all in Electrical Engineering. Since 1997, he has been an Associate Professor with the Department of Electronics and Computer Engineering, at Poli/UFRJ, and, since 1998, with the Program of Electrical Engineering, at COPPE/UFRJ. He is the co-author (with P. S. R. Diniz and E. A. B. da Silva) of "Digital Signal Processing: System Analysis and Design" by Cambridge University Press, 2nd ed., 2010. His teaching and research interests lie in the areas of digital signal processing, speech processing, information theory and math education.

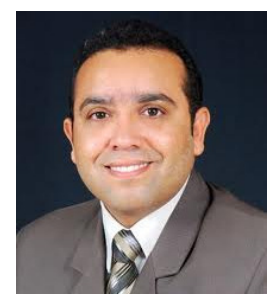

Moisés V. Ribeiro received the B.S. degree in Electrical Engineering from the Federal University of Juiz de Fora (UFJF), MG, Brazil, and M.Sc. and D.Sc. degrees in Electrical Engineering from the University of Campinas, SP, Brazil, in 1999, 2001 and 2005, respectively. He was a Visiting Scholar at University of California in Santa Barbara, CA, USA, in 2004, Visiting Professor (2005-2007) and Assistant Professor (2007-2015) at UFJF. Since 2015, he has been an Associate Professor at UFJF. He co-founded Smarti9 LTD. and Wari LTD. in 2012 and 2015, respectively. His research interests includes signal processing, digital communication, power line communication, smart grids, internet of things, industry 4.0 and smart city. In these fields, he has advised 38 graduate students and authored over 180 peer reviewed papers, 9 book chapters, and filed 13 patents. He was the General Chair of the 2010 IEEE ISPLC, 2013 IWSGC, SBrT 2015, and a Guest Co-Editor for Special Issues in the EURASIP Journal on Advances in Signal Processing and EURASIP Journal of Electrical and Computer Engineering. He had served as the Secretary of the IEEE ComSoc TC-PLC. He was the recipient of Fulbright Visiting Professorship at Stanford University, Stanford, CA, USA, in 2011, and at Princeton University, Princeton, NJ, USA, in 2012. He was awarded Student Awards from 2001 IEEE IECON and 2003 IEEE ISIE, Winner of 2014 I2P Global Competition, Honorable Mention in 2014 Global Venture Labs Investment Competition, 3rd Place Prêmio Mineiro de Inovação 2014, Engie Brazil Innovation Award 2016, Unicamp Inventor Award in 2017 and 2018. 


\section{APPENDIX \\ STATISTICAL MODELS FOR PLC CHANNEL FEATURES}

TABLE IV: The results of the statistical modeling of ACA for Band A.

\begin{tabular}{|c|c|c|c|c|c|}
\hline Distribution & Parameter estimate & MLE & AIC & BIC & EDC \\
\hline Exponential & $\mu=(23.2804 \pm 0.0820)$ & $-2.7412 \times 10^{4}$ & $5.4825 \times 10^{4}$ & $5.4827 \times 10^{4}$ & $5.4839 \times 10^{4}$ \\
\hline Gamma & $\begin{array}{l}a=(6.9369 \pm 0.0139) \\
b=(3.3560 \pm 0.0035)\end{array}$ & $-2.3451 \times 10^{4}$ & $4.6906 \times 10^{4}$ & $4.6909 \times 10^{4}$ & $4.6934 \times 10^{4}$ \\
\hline Inverse Gaussian & $\begin{array}{c}\mu=(23.2804 \pm 0.0137) \\
\lambda=(139.8050 \pm 5.9148)\end{array}$ & $-2.3525 \times 10^{4}$ & $4.7054 \times 10^{4}$ & $4.7057 \times 10^{4}$ & $4.7082 \times 10^{4}$ \\
\hline Logistic & $\begin{aligned} \mu & =(23.0296 \pm 0.0124) \\
\sigma & =(5.1032 \pm 0.0026)\end{aligned}$ & $-2.3802 \times 10^{4}$ & $4.7608 \times 10^{4}$ & $4.7612 \times 10^{4}$ & $4.7637 \times 10^{4}$ \\
\hline Log-logistic & $\begin{array}{l}\mu=(3.0939 \pm 0.2621) \\
\sigma=(0.2346 \pm 0.0556)\end{array}$ & $-2.3766 \times 10^{4}$ & $4.7536 \times 10^{4}$ & $4.7539 \times 10^{4}$ & $4.7564 \times 10^{4}$ \\
\hline Log-normal & $\begin{array}{l}\mu=\left(3.0738 \pm 0.2357 \times 10^{-4}\right) \\
\sigma=\left(0.3946 \pm 0.1179 \times 10^{-4}\right)\end{array}$ & $-2.3547 \times 10^{4}$ & $4.7099 \times 10^{4}$ & $4.7102 \times 10^{4}$ & $4.7127 \times 10^{4}$ \\
\hline Nakagami & $\begin{array}{c}\mu=(1.9633 \pm 0.0010) \\
\omega=(616.0890 \pm 29.2519)\end{array}$ & $-2.3434 \times 10^{4}$ & $4.6873 \times 10^{4}$ & $4.6876 \times 10^{4}$ & $4.6901 \times 10^{4}$ \\
\hline Normal & $\begin{array}{c}\mu=(23.2804 \pm 0.0112) \\
\sigma=(8.6094 \pm 0.0056)\end{array}$ & $-2.3606 \times 10^{4}$ & $4.7215 \times 10^{4}$ & $4.7219 \times 10^{4}$ & $4.7244 \times 10^{4}$ \\
\hline Rayleigh & $B=(17.5512 \pm 0.0117)$ & $-2.4165 \times 10^{4}$ & $4.8333 \times 10^{4}$ & $4.8335 \times 10^{4}$ & $4.8347 \times 10^{4}$ \\
\hline Rician & $\begin{array}{c}s=(21.1317 \pm 0.0174) \\
\sigma=(9.2071 \pm 0.0093)\end{array}$ & $-2.3542 \times 10^{4}$ & $4.7088 \times 10^{4}$ & $4.7092 \times 10^{4}$ & $4.7117 \times 10^{4}$ \\
\hline Skew-normal & $\begin{aligned} \mu & =(22.7062 \pm 0.0124) \\
\sigma & =(9.4122 \pm 0.0081) \\
\gamma & =(0.9625 \pm 0.0015)\end{aligned}$ & $-2.3359 \times 10^{4}$ & $4.6726 \times 10^{4}$ & $4.6731 \times 10^{4}$ & $4.6768 \times 10^{4}$ \\
\hline $\mathrm{t}$-Student & $\begin{array}{c}\mu=(23.2802 \pm 0.0112) \\
\sigma=(8.6091 \pm 0.0056) \\
\nu=\left(1.0684 \times 10^{7} \pm 3.0323 \times 10^{9}\right)\end{array}$ & $-2.3606 \times 10^{4}$ & $4.7217 \times 10^{4}$ & $4.7223 \times 10^{4}$ & $4.7260 \times 10^{4}$ \\
\hline Weibull & $\begin{array}{c}A=(26.1488 \pm 0.0132) \\
B=(2.9580 \pm 0.0008)\end{array}$ & $-2.3471 \times 10^{4}$ & $4.6945 \times 10^{4}$ & $4.6949 \times 10^{4}$ & $4.6974 \times 10^{4}$ \\
\hline
\end{tabular}

TABLE V: The results of the statistical modeling of ACA for Band B.

\begin{tabular}{|c|c|c|c|c|c|}
\hline Distribution & Parameter estimate & MLE & AIC & BIC & EDC \\
\hline Exponential & $\mu=(25.2440 \pm 0.0964)$ & $-2.7947 \times 10^{4}$ & $5.5895 \times 10^{4}$ & $5.5897 \times 10^{4}$ & $5.5910 \times 10^{4}$ \\
\hline Gamma & $\begin{array}{l}a=(8.5236 \pm 0.0212) \\
b=(2.9617 \pm 0.0027)\end{array}$ & $-2.3368 \times 10^{4}$ & $4.6741 \times 10^{4}$ & $4.6744 \times 10^{4}$ & $4.6769 \times 10^{4}$ \\
\hline Inverse Gaussian & $\begin{array}{c}\mu=(25.2440 \pm 0.0132) \\
\lambda=(184.5320 \pm 10.3958)\end{array}$ & $-2.3549 \times 10^{4}$ & $4.7102 \times 10^{4}$ & $4.7106 \times 10^{4}$ & $4.7131 \times 10^{4}$ \\
\hline Logistic & $\begin{aligned} \mu & =(25.1994 \pm 0.0109) \\
\sigma & =(4.8178 \pm 0.0024)\end{aligned}$ & $-2.3478 \times 10^{4}$ & $4.6960 \times 10^{4}$ & $4.6964 \times 10^{4}$ & $4.6988 \times 10^{4}$ \\
\hline Log-logistic & $\begin{array}{l}\mu=\left(3.1965 \pm 0.1971 \times 10^{-4}\right) \\
\sigma=\left(0.2058 \pm 0.0441 \times 10^{-4}\right)\end{array}$ & $-2.3630 \times 10^{4}$ & $4.7264 \times 10^{4}$ & $4.7268 \times 10^{4}$ & $4.7293 \times 10^{4}$ \\
\hline Log-normal & $\begin{array}{l}\mu=\left(3.1688 \pm 0.1947 \times 10^{-4}\right) \\
\sigma=\left(0.3587 \pm 0.0974 \times 10^{-4}\right)\end{array}$ & $-2.3543 \times 10^{4}$ & $4.7091 \times 10^{4}$ & $4.7094 \times 10^{4}$ & $4.7119 \times 10^{4}$ \\
\hline Nakagami & $\begin{array}{c}\mu=(2.4072 \pm 0.0015) \\
\omega=(705.8651 \pm 31.3180)\end{array}$ & $-2.3289 \times 10^{4}$ & $4.6582 \times 10^{4}$ & $4.6586 \times 10^{4}$ & $4.6611 \times 10^{4}$ \\
\hline Normal & $\begin{aligned} \mu & =(25.2445 \pm 0.0104) \\
\sigma & =(8.2835 \pm 0.0052)\end{aligned}$ & $-2.3350 \times 10^{4}$ & $4.6705 \times 10^{4}$ & $4.6708 \times 10^{4}$ & $4.6733 \times 10^{4}$ \\
\hline Rayleigh & $B=(18.7865 \pm 0.0134)$ & $-2.4437 \times 10^{4}$ & $4.8875 \times 10^{4}$ & $4.8877 \times 10^{4}$ & $4.8890 \times 10^{4}$ \\
\hline Rician & $\begin{array}{l}s=(23.3614 \pm 0.0135) \\
\sigma=(8.6429 \pm 0.0070)\end{array}$ & $-2.3326 \times 10^{4}$ & $4.6656 \times 10^{4}$ & $4.6660 \times 10^{4}$ & $4.6684 \times 10^{4}$ \\
\hline Skew-normal & $\begin{array}{c}\mu=\left(25.2377 \pm 1.0401 \times 10^{-2}\right) \\
\sigma=(8.2875 \pm 0.0054) \\
\gamma=\left(0.1779 \pm 1.1403 \times 10^{-3}\right)\end{array}$ & $-2.3335 \times 10^{4}$ & $4.6676 \times 10^{4}$ & $4.6682 \times 10^{4}$ & $4.6719 \times 10^{4}$ \\
\hline t-Student & $\begin{array}{c}\mu=(25.2445 \pm 0.0104) \\
\sigma=(8.2829 \pm 0.0052) \\
\nu=\left(1.2079 \times 10^{6} \pm 1.7073 \times 10^{9}\right)\end{array}$ & $-2.3350 \times 10^{4}$ & $4.6707 \times 10^{4}$ & $4.6712 \times 10^{4}$ & $4.6750 \times 10^{4}$ \\
\hline Weibull & $\begin{array}{c}A=(28.1449 \pm 0.0119) \\
B=(3.3479 \pm 0.0010)\end{array}$ & $-2.3296 \times 10^{4}$ & $4.6595 \times 10^{4}$ & $4.6599 \times 10^{4}$ & $4.6624 \times 10^{4}$ \\
\hline
\end{tabular}


TABLE VI: The results of the statistical modeling of ACA for Band C.

\begin{tabular}{|c|c|c|c|c|c|}
\hline Distribution & Parameter estimate & MLE & AIC & BIC & EDC \\
\hline Exponential & $\mu=(30.2112 \pm 0.1381)$ & $-2.9134 \times 10^{4}$ & $5.8270 \times 10^{4}$ & $5.8272 \times 10^{4}$ & $5.8284 \times 10^{4}$ \\
\hline Gamma & $\begin{aligned} a & =(10.1338 \pm 0.0301) \\
b & =(2.9812 \pm 0.0027)\end{aligned}$ & $-2.4027 \times 10^{4}$ & $4.8058 \times 10^{4}$ & $4.8062 \times 10^{4}$ & $4.8087 \times 10^{4}$ \\
\hline Inverse Gaussian & $\begin{array}{c}\mu=(30.2112 \pm 0.0154) \\
\lambda=(270.2152 \pm 22.0960)\end{array}$ & $-2.4165 \times 10^{4}$ & $4.8335 \times 10^{4}$ & $4.8338 \times 10^{4}$ & $4.8363 \times 10^{4}$ \\
\hline Logistic & $\begin{aligned} \mu & =(30.1738 \pm 0.0135) \\
\sigma & =(5.3523 \pm 0.0029)\end{aligned}$ & $-2.4163 \times 10^{4}$ & $4.8330 \times 10^{4}$ & $4.8333 \times 10^{4}$ & $4.8358 \times 10^{4}$ \\
\hline Log-logistic & $\begin{array}{l}\mu=\left(3.3809 \pm 0.1667 \times 10^{-4}\right) \\
\sigma=\left(0.1889 \pm 0.0369 \times 10^{-4}\right)\end{array}$ & $-2.4287 \times 10^{4}$ & $4.8577 \times 10^{4}$ & $4.8581 \times 10^{4}$ & $4.8606 \times 10^{4}$ \\
\hline Log-normal & $\begin{array}{l}\mu=\left(3.3581 \pm 0.1610 \times 10^{-4}\right) \\
\sigma=\left(0.3262 \pm 0.0805 \times 10^{-4}\right)\end{array}$ & $-2.4167 \times 10^{4}$ & $4.8339 \times 10^{4}$ & $4.8342 \times 10^{4}$ & $4.8367 \times 10^{4}$ \\
\hline Nakagami & $\begin{array}{c}\mu=(2.8123 \pm 0.0021) \\
\omega=(996.5721 \pm 53.4341)\end{array}$ & $-2.3962 \times 10^{4}$ & $4.7928 \times 10^{4}$ & $4.7931 \times 10^{4}$ & $4.7956 \times 10^{4}$ \\
\hline Normal & $\begin{array}{c}\mu=(30.2112 \pm 0.0127) \\
\sigma=(9.1581 \pm 0.0063)\end{array}$ & $-2.4014 \times 10^{4}$ & $4.8032 \times 10^{4}$ & $4.8035 \times 10^{4}$ & $4.8060 \times 10^{4}$ \\
\hline Rayleigh & $B=(22.3223 \pm 0.0188)$ & $-2.5465 \times 10^{4}$ & $5.0932 \times 10^{4}$ & $5.0934 \times 10^{4}$ & $5.0947 \times 10^{4}$ \\
\hline Rician & $\begin{array}{c}s=(28.5925 \pm 0.0155) \\
\sigma=(9.4616 \pm 0.0079)\end{array}$ & $-2.3998 \times 10^{4}$ & $4.8001 \times 10^{4}$ & $4.8005 \times 10^{4}$ & $4.8029 \times 10^{4}$ \\
\hline Skew-normal & $\begin{aligned} \mu & =\left(30.2037 \pm 1.2715 \times 10^{-2}\right) \\
\sigma & =\left(9.1627 \pm 0.6591 \times 10^{-2}\right) \\
\gamma & =\left(0.1488 \pm 1.2825 \times 10^{-3}\right)\end{aligned}$ & $-2.4004 \times 10^{4}$ & $4.8015 \times 10^{4}$ & $4.8020 \times 10^{4}$ & $4.8058 \times 10^{4}$ \\
\hline $\mathrm{t}$-Student & $\begin{array}{c}\mu=(30.2115 \pm 0.0127) \\
\sigma=(9.1574 \pm 0.0063) \\
\nu=\left(6.3036 \times 10^{6} \pm 2.9163 \times 10^{9}\right)\end{array}$ & $-2.4014 \times 10^{4}$ & $4.8034 \times 10^{4}$ & $4.8039 \times 10^{4}$ & $4.8076 \times 10^{4}$ \\
\hline Weibull & $\begin{array}{c}A=(33.5333 \pm 0.0143) \\
B=(3.6440 \pm 0.0012)\end{array}$ & $-2.3977 \times 10^{4}$ & $4.7957 \times 10^{4}$ & $4.7961 \times 10^{4}$ & $4.7986 \times 10^{4}$ \\
\hline
\end{tabular}

TABLE VII: The results of the statistical modeling of RMS-DS for Band A.

\begin{tabular}{|c|c|c|c|c|c|}
\hline Distribution & Parameter estimate & MLE & AIC & $\mathrm{BIC}$ & EDC \\
\hline Exponential & $\mu=\left(0.1481 \pm 3.3180 \times 10^{-6}\right)$ & $6.0141 \times 10^{3}$ & $-1.2026 \times 10^{4}$ & $-1.2024 \times 10^{4}$ & $-1.2012 \times 10^{4}$ \\
\hline Gamma & $\begin{array}{l}a=(5.3806 \pm 0.0083) \\
b=(0.0275 \pm 0.0002)\end{array}$ & $9.2350 \times 10^{3}$ & $-1.8466 \times 10^{4}$ & $-1.8462 \times 10^{4}$ & $-1.8437 \times 10^{4}$ \\
\hline Inverse Gaussian & $\begin{aligned} \mu & =\left(0.1481 \pm 0.0007 \times 10^{-3}\right) \\
\lambda & =\left(0.6674 \pm 0.1348 \times 10^{-3}\right)\end{aligned}$ & $9.1701 \times 10^{3}$ & $-1.8336 \times 10^{4}$ & $-1.8333 \times 10^{4}$ & $-1.8308 \times 10^{4}$ \\
\hline Logistic & $\begin{array}{c}\mu=\left(0.14373 \pm 0.5951 \times 10^{-6}\right) \\
\sigma=\left(0.0358 \pm 0.1321 \times 10^{-6}\right)\end{array}$ & $8.8357 \times 10^{3}$ & $-1.7667 \times 10^{4}$ & $-1.7664 \times 10^{4}$ & $-1.7639 \times 10^{4}$ \\
\hline Log-logistic & $\begin{array}{c}\mu=\left(-1.9881 \pm 0.3114 \times 10^{-4}\right) \\
\sigma=\left(0.2584 \pm 0.0687 \times 10^{-4}\right)\end{array}$ & $9.0858 \times 10^{3}$ & $-1.8168 \times 10^{4}$ & $-1.8164 \times 10^{4}$ & $-1.8139 \times 10^{4}$ \\
\hline Log-normal & $\begin{array}{c}\mu=\left(-2.1459 \pm 0.4191 \times 10^{-4}\right) \\
\sigma=\left(0.5263 \pm 0.2096 \times 10^{-4}\right)\end{array}$ & $9.0471 \times 10^{3}$ & $-1.8090 \times 10^{4}$ & $-1.8087 \times 10^{4}$ & $-1.8062 \times 10^{4}$ \\
\hline Nakagami & $\begin{array}{l}\mu=\left(1.5153 \pm 0.5768 \times 10^{-3}\right) \\
\omega=\left(0.0261 \pm 0.0001 \times 10^{-3}\right)\end{array}$ & $9.1241 \times 10^{3}$ & $-1.8244 \times 10^{4}$ & $-1.8241 \times 10^{4}$ & $-1.8216 \times 10^{4}$ \\
\hline Normal & $\begin{array}{l}\mu=\left(0.1481 \pm 0.6280 \times 10^{-6}\right) \\
\sigma=\left(0.0644 \pm 0.0644 \times 10^{-4}\right)\end{array}$ & $8.7462 \times 10^{3}$ & $-1.7488 \times 10^{4}$ & $-1.7485 \times 10^{4}$ & $-1.7460 \times 10^{4}$ \\
\hline Rayleigh & $B=\left(0.1142 \pm 4.9324 \times 10^{-7}\right)$ & $8.8165 \times 10^{3}$ & $-1.7631 \times 10^{4}$ & $-1.7629 \times 10^{4}$ & $-1.7617 \times 10^{4}$ \\
\hline Rician & $\begin{array}{l}s=\left(0.1222 \pm 0.2104 \times 10^{-5}\right) \\
\sigma=\left(0.0746 \pm 0.1056 \times 10^{-5}\right)\end{array}$ & $8.9461 \times 10^{3}$ & $-1.7888 \times 10^{4}$ & $-1.7885 \times 10^{4}$ & $-1.7860 \times 10^{4}$ \\
\hline Skew-normal & $\begin{array}{l}\mu=\left(0.1477 \pm 6.2367 \times 10^{-7}\right) \\
\sigma=\left(0.0649 \pm 4.1255 \times 10^{-7}\right) \\
\gamma=\left(0.8453 \pm 1.7173 \times 10^{-4}\right)\end{array}$ & $9.2045 \times 10^{3}$ & $-1.8403 \times 10^{4}$ & $-1.8398 \times 10^{4}$ & $-1.8360 \times 10^{4}$ \\
\hline $\mathrm{t}$-Student & $\begin{array}{c}\mu=\left(0.1442 \pm 6.2515 \times 10^{-7}\right) \\
\sigma=\left(0.0566 \pm 5.1078 \times 10^{-7}\right) \\
\nu=(9.2055 \pm 0.6177)\end{array}$ & $8.8602 \times 10^{3}$ & $-1.7714 \times 10^{4}$ & $-1.7709 \times 10^{4}$ & $-1.7672 \times 10^{4}$ \\
\hline Weibull & $\begin{array}{l}A=\left(0.1672 \pm 0.0008 \times 10^{-3}\right) \\
B=\left(2.4300 \pm 0.4811 \times 10^{-3}\right)\end{array}$ & $9.0239 \times 10^{3}$ & $-1.8044 \times 10^{4}$ & $-1.8040 \times 10^{4}$ & $-1.8015 \times 10^{4}$ \\
\hline
\end{tabular}


TABLE VIII: The results of the statistical modeling of RMS-DS for Band B.

\begin{tabular}{|c|c|c|c|c|c|}
\hline Distribution & Parameter estimate & MLE & AIC & BIC & EDC \\
\hline Exponential & $\mu=\left(0.1384 \pm 2.8962 \times 10^{-6}\right)$ & $6.4634 \times 10^{3}$ & $-1.2925 \times 10^{4}$ & $-1.2923 \times 10^{4}$ & $-1.2911 \times 10^{4}$ \\
\hline Gamma & $\begin{array}{l}a=(4.6809 \pm 0.0062) \\
b=(0.0295 \pm 0.0004)\end{array}$ & $9.2915 \times 10^{3}$ & $-1.8579 \times 10^{4}$ & $-1.8575 \times 10^{4}$ & $-1.8550 \times 10^{4}$ \\
\hline Inverse Gaussian & $\begin{array}{l}\mu=\left(0.1384 \pm 0.0078 \times 10^{-4}\right) \\
\lambda=\left(0.5105 \pm 0.7888 \times 10^{-4}\right)\end{array}$ & $9.1057 \times 10^{3}$ & $-1.8207 \times 10^{4}$ & $-1.8204 \times 10^{4}$ & $-1.8179 \times 10^{4}$ \\
\hline Logistic & $\begin{array}{l}\mu=\left(0.1342 \pm 0.5661 \times 10^{-6}\right) \\
\sigma=\left(0.0351 \pm 0.1274 \times 10^{-6}\right)\end{array}$ & $8.9580 \times 10^{3}$ & $-1.7912 \times 10^{4}$ & $-1.7908 \times 10^{4}$ & $-1.7883 \times 10^{4}$ \\
\hline Log-logistic & $\begin{array}{c}\mu=\left(-2.0601 \pm 0.3524 \times 10^{-4}\right) \\
\sigma=\left(0.2767 \pm 0.0801 \times 10^{-4}\right)\end{array}$ & $9.1259 \times 10^{3}$ & $-1.8248 \times 10^{4}$ & $-1.8244 \times 10^{4}$ & $-1.8219 \times 10^{4}$ \\
\hline Log-normal & $\begin{array}{c}\mu=\left(-2.0886 \pm 0.3625 \times 10^{-4}\right) \\
\sigma=\left(0.4895 \pm 0.1813 \times 10^{-4}\right)\end{array}$ & $9.1479 \times 10^{3}$ & $-1.8292 \times 10^{4}$ & $-1.8288 \times 10^{4}$ & $-1.8263 \times 10^{4}$ \\
\hline Nakagami & $\begin{array}{l}\mu=\left(1.3543 \pm 0.4528 \times 10^{-3}\right) \\
\omega=\left(0.0232 \pm 0.0001 \times 10^{-3}\right)\end{array}$ & $9.2203 \times 10^{3}$ & $-1.8347 \times 10^{4}$ & $-1.8433 \times 10^{4}$ & $-1.8408 \times 10^{4}$ \\
\hline Normal & $\begin{array}{l}\mu=\left(0.1384 \pm 0.6109 \times 10^{-6}\right) \\
\sigma=\left(0.0635 \pm 0.3055 \times 10^{-6}\right)\end{array}$ & $8.8374 \times 10^{3}$ & $-1.7671 \times 10^{4}$ & $-1.7667 \times 10^{4}$ & $-1.7642 \times 10^{4}$ \\
\hline Rayleigh & $B=\left(0.1076 \pm 4.3838 \times 10^{-7}\right)$ & $9.0486 \times 10^{3}$ & $-1.8095 \times 10^{4}$ & $-1.8093 \times 10^{4}$ & $-1.8081 \times 10^{4}$ \\
\hline Rician & $\begin{array}{l}s=\left(0.1062 \pm 0.3890 \times 10^{-5}\right) \\
\sigma=\left(0.0771 \pm 0.1642 \times 10^{-5}\right)\end{array}$ & $9.0973 \times 10^{3}$ & $-1.8191 \times 10^{4}$ & $-1.8187 \times 10^{4}$ & $-1.8162 \times 10^{4}$ \\
\hline Skew-normal & $\begin{array}{l}\mu=\left(0.1383 \pm 6.0740 \times 10^{-7}\right) \\
\sigma=\left(0.0636 \pm 3.9489 \times 10^{-7}\right) \\
\lambda=\left(0.7747 \pm 3.1647 \times 10^{-4}\right)\end{array}$ & $9.2278 \times 10^{3}$ & $-1.8450 \times 10^{4}$ & $-1.8444 \times 10^{4}$ & $-1.8407 \times 10^{4}$ \\
\hline $\mathrm{t}$-Student & $\begin{array}{c}\mu=\left(0.1344 \pm 5.8888 \times 10^{-7}\right) \\
\sigma=\left(0.0548 \pm 5.0551 \times 10^{-7}\right) \\
\nu=(8.1067 \pm 0.4104)\end{array}$ & $8.9774 \times 10^{3}$ & $-1.7949 \times 10^{4}$ & $-1.7943 \times 10^{4}$ & $-1.7906 \times 10^{4}$ \\
\hline Weibull & $\begin{array}{l}A=\left(0.1564 \pm 0.0008 \times 10^{-3}\right) \\
B=\left(2.3007 \pm 0.4367 \times 10^{-3}\right)\end{array}$ & $9.1580 \times 10^{3}$ & $-1.8312 \times 10^{4}$ & $-1.8308 \times 10^{4}$ & $-1.8283 \times 10^{4}$ \\
\hline
\end{tabular}

TABLE IX: The results of the statistical modeling of RMS-DS for Band C.

\begin{tabular}{|c|c|c|c|c|c|}
\hline Distribution & Parameter estimate & MLE & AIC & $\mathrm{BIC}$ & EDC \\
\hline Exponential & $\mu=\left(0.1327 \pm 2.6647 \times 10^{-6}\right)$ & $6.7386 \times 10^{3}$ & $-1.3475 \times 10^{4}$ & $-1.3473 \times 10^{4}$ & $-1.3461 \times 10^{4}$ \\
\hline Gamma & $\begin{array}{l}a=(4.1178 \pm 0.0048) \\
b=(0.0322 \pm 0.0001)\end{array}$ & $9.2151 \times 10^{3}$ & $-1.8426 \times 10^{4}$ & $-1.8423 \times 10^{4}$ & $-1.8398 \times 10^{4}$ \\
\hline Inverse Gaussian & $\begin{aligned} \mu & =\left(0.1327 \pm 0.0085 \times 10^{-4}\right) \\
\lambda & =\left(0.4167 \pm 0.5256 \times 10^{-4}\right)\end{aligned}$ & $9.0035 \times 10^{3}$ & $-1.8003 \times 10^{4}$ & $-1.7999 \times 10^{4}$ & $-1.7974 \times 10^{4}$ \\
\hline Logistic & $\begin{array}{l}\mu=\left(0.1285 \pm 0.5914 \times 10^{-6}\right) \\
\sigma=\left(0.0358 \pm 0.1324 \times 10^{-6}\right)\end{array}$ & $8.8334 \times 10^{3}$ & $-1.7663 \times 10^{4}$ & $-1.7659 \times 10^{4}$ & $-1.7634 \times 10^{4}$ \\
\hline Log-logistic & $\begin{array}{c}\mu=\left(-2.1128 \pm 0.4106 \times 10^{-4}\right) \\
\sigma=\left(0.2984 \pm 0.0932 \times 10^{-3}\right)\end{array}$ & $9.0088 \times 10^{3}$ & $-1.8014 \times 10^{4}$ & $-1.8010 \times 10^{4}$ & $-1.7985 \times 10^{4}$ \\
\hline Log-normal & $\begin{array}{c}\mu=\left(-2.1459 \pm 0.4191 \times 10^{-4}\right) \\
\sigma=\left(0.5263 \pm 0.2096 \times 10^{-4}\right)\end{array}$ & $9.0471 \times 10^{3}$ & $-1.8090 \times 10^{4}$ & $-1.8087 \times 10^{4}$ & $-1.8062 \times 10^{4}$ \\
\hline Nakagami & $\begin{array}{l}\mu=\left(1.2160 \pm 0.3587 \times 10^{-3}\right) \\
\omega=\left(0.0218 \pm 0.0001 \times 10^{-3}\right)\end{array}$ & $9.1591 \times 10^{3}$ & $-1.8314 \times 10^{4}$ & $-1.8311 \times 10^{4}$ & $-1.8286 \times 10^{4}$ \\
\hline Normal & $\begin{array}{l}\mu=\left(0.1327 \pm 0.6290 \times 10^{-6}\right) \\
\sigma=\left(0.0645 \pm 0.3146 \times 10^{-6}\right)\end{array}$ & $8.7409 \times 10^{3}$ & $-1.7478 \times 10^{4}$ & $-1.7474 \times 10^{4}$ & $-1.7449 \times 10^{4}$ \\
\hline Rayleigh & $B=\left(0.1043 \pm 4.1171 \times 10^{-7}\right)$ & $9.0844 \times 10^{3}$ & $-1.8167 \times 10^{4}$ & $-1.8165 \times 10^{4}$ & $-1.8152 \times 10^{4}$ \\
\hline Rician & $\begin{array}{c}s=\left(0.1940 \times 10^{-3} \pm 0.3422 \times 10^{-5}\right) \\
\sigma=\left(0.1043 \pm 0.0177 \times 10^{-5}\right)\end{array}$ & $9.0844 \times 10^{3}$ & $-1.8165 \times 10^{4}$ & $-1.8161 \times 10^{4}$ & $-1.8136 \times 10^{4}$ \\
\hline Skew-normal & $\begin{array}{l}\mu=\left(0.1323 \pm 6.3203 \times 10^{-7}\right) \\
\sigma=\left(0.0649 \pm 4.2056 \times 10^{-7}\right) \\
\lambda=\left(0.8127 \pm 2.6454 \times 10^{-4}\right)\end{array}$ & $9.1509 \times 10^{3}$ & $-1.8296 \times 10^{4}$ & $-1.8290 \times 10^{4}$ & $-1.8253 \times 10^{4}$ \\
\hline t-Student & $\begin{array}{c}\mu=\left(0.1288 \pm 6.2274 \times 10^{-7}\right) \\
\sigma=\left(0.0564 \pm 5.3258 \times 10^{-7}\right) \\
\nu=(8.8234 \pm 0.5668)\end{array}$ & $8.8528 \times 10^{3}$ & $-1.7700 \times 10^{4}$ & $-1.7694 \times 10^{4}$ & $-1.7657 \times 10^{4}$ \\
\hline Weibull & $\begin{array}{l}A=\left(0.1484 \pm 0.0008 \times 10^{-3}\right) \\
B=\left(2.1794 \pm 0.4020 \times 10^{-3}\right)\end{array}$ & $9.1259 \times 10^{3}$ & $-1.8248 \times 10^{4}$ & $-1.8244 \times 10^{4}$ & $-1.8219 \times 10^{4}$ \\
\hline
\end{tabular}


TABLE X: The results of the statistical modeling of CB for Band A.

\begin{tabular}{|c|c|c|c|c|c|}
\hline \multicolumn{7}{|c|}{ CB for Band A } \\
\hline Distribution & Parameter estimate & MLE & AIC & BIC & EDC \\
\hline Exponential & $\mu=\left(0.7049 \pm 8.5353 \times 10^{-5}\right)$ & $-3.7828 \times 10^{3}$ & $7.5677 \times 10^{3}$ & $7.5694 \times 10^{3}$ & $7.5809 \times 10^{3}$ \\
\hline Gamma & $a=(2.8401 \pm 0.0025)$ & $-2.4386 \times 10^{3}$ & $4.8811 \times 10^{3}$ & $4.8847 \times 10^{3}$ & $4.9077 \times 10^{3}$ \\
& $b=(0.2481 \pm 0.0003)$ & & & & \\
\hline Inverse Gaussian & $\mu=\left(0.7047 \pm 0.0360 \times 10^{-3}\right)$ & $-2.0820 \times 10^{3}$ & $4.1681 \times 10^{3}$ & $4.1716 \times 10^{3}$ & $4.1946 \times 10^{3}$ \\
& $\sigma=\left(1.6715 \pm 0.9603 \times 10^{-3}\right)$ & & & \\
\hline Logistic & $\mu=\left(0.6209 \pm 0.2684 \times 10^{-4}\right)$ & $-3.5161 \times 10^{3}$ & $7.0363 \times 10^{3}$ & $7.0398 \times 10^{3}$ & $7.0628 \times 10^{3}$ \\
& $\sigma=\left(0.2348 \pm 0.0717 \times 10^{-4}\right)$ & & & & \\
\hline Log-logistic & $\mu=\left(-0.5605 \pm 0.5852 \times 10^{-4}\right)$ & $-2.1168 \times 10^{3}$ & $4.2375 \times 10^{3}$ & $4.2411 \times 10^{3}$ & $4.2640 \times 10^{3}$ \\
& $\sigma=\left(0.3351 \pm 0.1340 \times 10^{-4}\right)$ & & & \\
\hline Log-normal & $\mu=\left(-0.5362 \pm 0.6042 \times 10^{-4}\right)$ & $-2.0949 \times 10^{3}$ & $4.1937 \times 10^{3}$ & $4.1973 \times 10^{3}$ & $4.2202 \times 10^{3}$ \\
& $\sigma=\left(0.5929 \pm 0.3022 \times 10^{-4}\right)$ & & & & \\
\hline Nakagami & $\mu=\left(0.78001 \pm 0.1550 \times 10^{-3}\right)$ & $-2.9776 \times 10^{3}$ & $5.9592 \times 10^{3}$ & $5.9627 \times 10^{3}$ & $5.9857 \times 10^{3}$ \\
& $\omega=\left(0.7342 \pm 0.1187 \times 10^{-3}\right)$ & & & & \\
\hline Normal & $\mu=\left(0.7047 \pm 0.4082 \times 10^{-4}\right)$ & $-4.0741 \times 10^{3}$ & $8.1522 \times 10^{3}$ & $8.1558 \times 10^{3}$ & $8.1787 \times 10^{3}$ \\
& $\sigma=\left(0.4874 \pm 0.2042 \times 10^{-4}\right)$ & & & & \\
\hline Rayleigh & $B=\left(0.6059 \pm 1.5771 \times 10^{-5}\right)$ & $-3.1074 \times 10^{3}$ & $6.2168 \times 10^{3}$ & $6.2186 \times 10^{3}$ & $6.2301 \times 10^{3}$ \\
\hline Rician & $s=(0.0006 \pm 44.5535)$ & $-3.1074 \times 10^{3}$ & $6.2188 \times 10^{3}$ & $6.2224 \times 10^{3}$ & $6.2453 \times 10^{3}$ \\
& $\sigma=(0.6059 \pm 0.0002)$ & & & & \\
\hline \multirow{2}{*}{ Skew-normal } & $\mu=\left(0.7571 \pm 2.9376 \times 10^{-5}\right)$ & $-2.4792 \times 10^{3}$ & $4.9645 \times 10^{3}$ & $4.9698 \times 10^{3}$ & $5.0043 \times 10^{3}$ \\
& $\sigma=\left(0.4262 \pm 1.7408 \times 10^{-5}\right)$ & & & & \\
\hline \multirow{2}{*}{ t-Student } & $\gamma=\left(0.9695 \pm 7.6399 \times 10^{-6}\right)$ & & & & \\
\hline Weibull & $\quad \sigma=\left(0.5512 \pm 0.1816 \times 10^{-4}\right)$ & $-2.9988 \times 10^{3}$ & $6.0035 \times 10^{3}$ & $6.0088 \times 10^{3}$ & $6.0433 \times 10^{3}$ \\
& $\sigma=\left(0.2318 \pm 0.1693 \times 10^{-4}\right)$ & & & & \\
\hline & $A=\left(0.7943 \pm 0.0473 \times 10^{-3}\right)$ & $-2.7952 \times 10^{3}$ & $5.5944 \times 10^{3}$ & $5.5979 \times 10^{3}$ & $5.6209 \times 10^{3}$ \\
& $B=\left(1.6091 \pm 0.2242 \times 10^{-3}\right)$ & & & & \\
\hline
\end{tabular}

TABLE XI: The results of the statistical modeling of CB for Band B.

\begin{tabular}{|c|c|c|c|c|c|}
\hline Distribution & Parameter estimate & MLE & AIC & BIC & EDC \\
\hline Exponential & $\mu=\left(0.6808 \pm 8.6105 \times 10^{-5}\right)$ & $-3.3134 \times 10^{3}$ & $6.6288 \times 10^{3}$ & $6.6305 \times 10^{3}$ & $6.6414 \times 10^{3}$ \\
\hline Gamma & $\begin{array}{c}a=(3.2404 \pm 0.0035) \\
b=\left(0.2101 \pm 0.1742 \times 10^{-4}\right)\end{array}$ & $-1.8063 \times 10^{3}$ & $3.6167 \times 10^{3}$ & $3.6202 \times 10^{3}$ & $3.6421 \times 10^{3}$ \\
\hline Inverse Gaussian & $\begin{array}{c}\mu=\left(0.6808 \pm 0.3224 \times 10^{-4}\right) \\
\sigma=(1.8182 \pm 0.0012)\end{array}$ & $-1.6152 \times 10^{3}$ & $3.2344 \times 10^{3}$ & $3.2378 \times 10^{3}$ & $3.2597 \times 10^{3}$ \\
\hline Logistic & $\begin{array}{l}\mu=\left(0.6156 \pm 0.2239 \times 10^{-4}\right) \\
\sigma=\left(0.2062 \pm 0.0582 \times 10^{-4}\right)\end{array}$ & $-2.5392 \times 10^{3}$ & $5.0825 \times 10^{3}$ & $5.0859 \times 10^{3}$ & $5.1078 \times 10^{3}$ \\
\hline Log-logistic & $\begin{array}{c}\mu=\left(-0.5518 \pm 0.5466 \times 10^{-4}\right) \\
\sigma=\left(0.3126 \pm 0.1266 \times 10^{-4}\right)\end{array}$ & $-1.5519 \times 10^{3}$ & $3.1078 \times 10^{3}$ & $3.1112 \times 10^{3}$ & $3.1331 \times 10^{3}$ \\
\hline Log-normal & $\begin{array}{c}\mu=\left(-0.5466 \pm 0.0584 \times 10^{-3}\right) \\
\sigma=\left(0.5608 \pm 0.0292 \times 10^{-3}\right)\end{array}$ & $-1.5821 \times 10^{3}$ & $3.1682 \times 10^{3}$ & $3.1717 \times 10^{3}$ & $3.1935 \times 10^{3}$ \\
\hline Nakagami & $\begin{array}{l}\mu=\left(0.8755 \pm 0.2155 \times 10^{-3}\right) \\
\omega=\left(0.6549 \pm 0.0910 \times 10^{-3}\right)\end{array}$ & $-2.2836 \times 10^{3}$ & $4.5713 \times 10^{3}$ & $4.5747 \times 10^{3}$ & $4.5966 \times 10^{3}$ \\
\hline Normal & $\begin{array}{l}\mu=\left(0.6808 \pm 0.3557 \times 10^{-4}\right) \\
\sigma=\left(0.4376 \pm 0.1779 \times 10^{-4}\right)\end{array}$ & $-3.1887 \times 10^{3}$ & $6.3815 \times 10^{3}$ & $6.3849 \times 10^{3}$ & $6.4068 \times 10^{3}$ \\
\hline Rayleigh & $B=\left(0.5722 \pm 1.5209 \times 10^{-5}\right)$ & $-2.3163 \times 10^{3}$ & $4.6345 \times 10^{3}$ & $4.6363 \times 10^{3}$ & $4.6472 \times 10^{3}$ \\
\hline Rician & $\begin{array}{c}s=(0.0135 \pm 0.0823) \\
\sigma=\left(0.5723 \pm 0.2677 \times 10^{-4}\right)\end{array}$ & $-3.1074 \times 10^{3}$ & $4.6365 \times 10^{3}$ & $4.6400 \times 10^{3}$ & $4.6619 \times 10^{3}$ \\
\hline Skew-normal & $\begin{array}{l}\mu=\left(0.7852 \pm 0.2471 \times 10^{-4}\right) \\
\sigma=\left(0.4151 \pm 0.1412 \times 10^{-4}\right) \\
\gamma=\left(0.9777 \pm 0.0026 \times 10^{-4}\right)\end{array}$ & $-2.5880 \times 10^{3}$ & $5.1821 \times 10^{3}$ & $5.1876 \times 10^{3}$ & $5.2249 \times 10^{3}$ \\
\hline t-Student & $\begin{array}{c}\mu=\left(0.5777 \pm 0.1714 \times 10^{-4}\right) \\
\sigma=\left(0.2304 \pm 0.1485 \times 10^{-4}\right) \\
\nu=(2.4015 \pm 0.0072)\end{array}$ & $-2.1428 \times 10^{3}$ & $4.2917 \times 10^{3}$ & $4.2969 \times 10^{3}$ & $4.3297 \times 10^{3}$ \\
\hline Weibull & $\begin{array}{l}A=\left(0.7695 \pm 0.0423 \times 10^{-3}\right) \\
B=\left(1.7123 \pm 0.2658 \times 10^{-3}\right)\end{array}$ & $-2.1687 \times 10^{3}$ & $4.3414 \times 10^{3}$ & $4.3448 \times 10^{3}$ & $3.3667 \times 10^{3}$ \\
\hline
\end{tabular}


TABLE XII: The results of the statistical modeling of CB for Band C.

\begin{tabular}{|c|c|c|c|c|c|}
\hline Distribution & Parameter estimate & MLE & AIC & BIC & EDC \\
\hline Exponential & $\mu=\left(0.8205 \pm 1.0187 \times 10^{-4}\right)$ & $-5.3016 \times 10^{3}$ & $1.0605 \times 10^{4}$ & $1.0607 \times 10^{4}$ & $1.0619 \times 10^{4}$ \\
\hline Gamma & $\begin{array}{l}a=(2.4376 \pm 0.0016) \\
b=(0.3366 \pm 0.0001)\end{array}$ & $-4.1263 \times 10^{3}$ & $8.2565 \times 10^{3}$ & $8.2602 \times 10^{3}$ & $8.2850 \times 10^{3}$ \\
\hline Inverse Gaussian & $\begin{array}{l}\mu=\left(0.8205 \pm 0.0473 \times 10^{-3}\right) \\
\sigma=\left(1.7677 \pm 0.9456 \times 10^{-3}\right)\end{array}$ & $-3.3638 \times 10^{3}$ & $6.7317 \times 10^{3}$ & $6.7353 \times 10^{3}$ & $6.7602 \times 10^{3}$ \\
\hline Logistic & $\begin{array}{l}\mu=\left(0.6901 \pm 0.3653 \times 10^{-4}\right) \\
\sigma=\left(0.2964 \pm 0.1048 \times 10^{-4}\right)\end{array}$ & $-5.7185 \times 10^{3}$ & $1.1441 \times 10^{4}$ & $1.1445 \times 10^{4}$ & $1.1470 \times 10^{4}$ \\
\hline Log-logistic & $\begin{array}{c}\mu=\left(-0.4703 \pm 0.5356 \times 10^{-4}\right) \\
\sigma=\left(0.3427 \pm 0.1249 \times 10^{-4}\right)\end{array}$ & $-3.3850 \times 10^{3}$ & $6.7739 \times 10^{3}$ & $6.7776 \times 10^{3}$ & $6.8024 \times 10^{3}$ \\
\hline Log-normal & $\begin{array}{c}\mu=\left(-0.4167 \pm 0.5735 \times 10^{-4}\right) \\
\sigma=\left(0.6156 \pm 0.2868 \times 10^{-4}\right)\end{array}$ & $-3.4170 \times 10^{3}$ & $6.8380 \times 10^{3}$ & $6.8417 \times 10^{3}$ & $6.8665 \times 10^{3}$ \\
\hline Nakagami & $\begin{array}{c}\mu=\left(0.6464 \pm 0.0904 \times 10^{-3}\right) \\
\omega=\left(1.11856 \pm 0.2929 \times 10^{-3}\right)\end{array}$ & $-5.0245 \times 10^{3}$ & $1.0053 \times 10^{4}$ & $1.0057 \times 10^{4}$ & $1.0082 \times 10^{4}$ \\
\hline Normal & $\begin{array}{l}\mu=\left(0.8205 \pm 0.6739 \times 10^{-4}\right) \\
\sigma=\left(0.6673 \pm 0.3370 \times 10^{-4}\right)\end{array}$ & $-6.7045 \times 10^{3}$ & $1.3413 \times 10^{4}$ & $1.3417 \times 10^{4}$ & $1.3441 \times 10^{4}$ \\
\hline Rayleigh & $B=\left(0.7478 \pm 2.1156 \times 10^{-5}\right)$ & $-5.5227 \times 10^{3}$ & $1.1047 \times 10^{4}$ & $1.1049 \times 10^{4}$ & $1.1062 \times 10^{4}$ \\
\hline Rician & $\begin{array}{l}s=(0.0187 \pm 0.0558) \\
\sigma=(0.7477 \pm 0.0002)\end{array}$ & $-5.5227 \times 10^{3}$ & $1.1049 \times 10^{4}$ & $1.1053 \times 10^{4}$ & $1.1078 \times 10^{4}$ \\
\hline Skew-normal & $\begin{array}{l}\mu=\left(0.9349 \pm 4.1300 \times 10^{-5}\right) \\
\sigma=\left(0.5425 \pm 2.3862 \times 10^{-5}\right) \\
\gamma=\left(0.9903 \pm 1.0703 \times 10^{-6}\right)\end{array}$ & $-4.2329 \times 10^{3}$ & $8.4719 \times 10^{3}$ & $8.4772 \times 10^{3}$ & $8.5117 \times 10^{3}$ \\
\hline $\mathrm{t}$-Student & $\begin{array}{c}\mu=\left(0.5703 \pm 0.1704 \times 10^{-4}\right) \\
\sigma=\left(0.2239 \pm 0.1561 \times 10^{-4}\right) \\
\nu=(1.4647 \pm 0.0014)\end{array}$ & $-4.4368 \times 10^{3}$ & $8.8797 \times 10^{3}$ & $8.8851 \times 10^{3}$ & $8.9225 \times 10^{3}$ \\
\hline Weibull & $\begin{array}{l}A=\left(0.9156 \pm 0.0698 \times 10^{-3}\right) \\
B=\left(1.4356 \pm 0.1494 \times 10^{-3}\right)\end{array}$ & $-4.5826 \times 10^{3}$ & $9.1692 \times 10^{3}$ & $9.1729 \times 10^{3}$ & $9.1978 \times 10^{3}$ \\
\hline
\end{tabular}

TABLE XIII: The results of the statistical modeling of CT for Band A.

\begin{tabular}{|c|c|c|c|c|c|}
\hline Distribution & Parameter estimate & MLE & AIC & BIC & EDC \\
\hline Exponential & $\mu=(1.1863 \pm 0.0079)$ & -208.4095 & 418.8191 & 419.0695 & 419.4874 \\
\hline Gamma & $a=(8.2153 \pm 0.7288)$ & -88.1016 & 180.2032 & 180.7040 & 181.5399 \\
& $b=(0.1444 \pm 0.0002)$ & & & & \\
\hline Inverse Gaussian & $\mu=(1.1863 \pm 0.0015)$ & -177.1688 & 238.3375 & 238.8384 & 238.6742 \\
& $\lambda=(6.3446 \pm 0.4523)$ & & & & \\
\hline Logistic & $\mu=\left(1.2413 \pm 0.6095 \times 10^{-3}\right)$ & -59.7283 & 123.4566 & 123.9575 & 124.7933 \\
& $\sigma=\left(0.1883 \pm 0.1440 \times 10^{-3}\right)$ & & & & \\
\hline Log-logistic & $\mu=\left(1.1858 \pm 0.6190 \times 10^{-3}\right)$ & -92.6302 & 189.2604 & 189.7613 & 190.5971 \\
& $\sigma=\left(0.1949 \pm 0.1642 \times 10^{-3}\right)$ & & & & \\
\hline Log-normal & $\mu=\left(1.1087 \pm 0.8980 \times 10^{-3}\right)$ & -108.2377 & 220.4754 & 220.9762 & 221.8121 \\
& $\sigma=\left(0.3998 \pm 0.4528 \times 10^{-3}\right)$ & & & & \\
\hline Nakagami & $\mu=(2.6184 \pm 0.0685)$ & -74.1036 & 152.2072 & 152.7080 & 153.5438 \\
& $\omega=(1.5226 \pm 0.0050)$ & & & & \\
\hline Normal & $\mu=\left(1.1863 \pm 0.6515 \times 10^{-3}\right)$ & -60.3188 & 124.6375 & 125.1384 & 125.9742 \\
& $\sigma=\left(0.3405 \pm 0.3285 \times 10^{-3}\right)$ & & & & \\
\hline Rayleigh & $B=(0.8725 \pm 0.0011)$ & -110.0999 & 222.1998 & 222.4502 & 222.8681 \\
\hline Rician & $s=\left(1.1305 \pm 0.7709 \times 10^{-3}\right)$ & -61.3467 & 126.6934 & 127.1942 & 128.0301 \\
& $\sigma=\left(0.3496 \pm 0.3919 \times 10^{-3}\right)$ & & & & \\
\hline \multirow{2}{*}{ Skew-normal } & $\mu=(1.1440 \pm 0.0004)$ & -3.5299 & 13.0597 & 13.8110 & 15.0647 \\
& $\sigma=(0.2909 \pm 0.0002)$ & & & & \\
\hline \multirow{2}{*}{ t-Student } & $\gamma=\left(-0.9898 \pm 1.412310^{-5}\right)$ & & & & \\
\hline Weibull & $\mu=\left(1.3867 \pm 5.6459 \times 10^{-4}\right)$ & -57.7546 & 121.5093 & 122.2605 & 123.5143 \\
& $\sigma=(0.1204 \pm 0.0011)$ & & & & \\
\hline & $\nu=(1.0848 \pm 0.0878)$ & & & & \\
\hline & $B=(1.3027 \pm 0.0005)$ & -53.8489 & 111.6979 & 112.1987 & 113.0345 \\
& $B=(4.5431 \pm 0.0939)$ & & & & \\
\hline
\end{tabular}


TABLE XIV: The results of the statistical modeling of CT for Band B.

\begin{tabular}{|c|c|c|c|c|c|}
\hline Distribution & Parameter estimate & MLE & AIC & BIC & EDC \\
\hline Exponential & $\mu=(1.1374 \pm 0.0073)$ & -200.9125 & 403.8249 & 404.0753 & 404.4932 \\
\hline Gamma & $a=(6.7627 \pm 0.4898)$ & -96.2638 & 196.5276 & 197.0285 & 197.8643 \\
& $b=(0.1682 \pm 0.0003)$ & & & & \\
\hline Inverse Gaussian & $\mu=(1.1374 \pm 0.0019)$ & -136.0928 & 276.1856 & 276.6864 & 277.5222 \\
& $\lambda=(4.3390 \pm 0.2115)$ & & & & \\
\hline Logistic & $\mu=\left(1.1850 \pm 0.6431 \times 10^{-3}\right)$ & -63.5261 & 131.0521 & 131.5530 & 132.3888 \\
& $\sigma=\left(0.1924 \pm 0.1485 \times 10^{-3}\right)$ & & & & \\
\hline Log-logistic & $\mu=\left(0.1366 \pm 0.7225 \times 10^{-3}\right)$ & -99.3000 & 202.6000 & 203.1009 & 203.9367 \\
& $\sigma=\left(0.2122 \pm 0.1921 \times 10^{-3}\right)$ & & & & \\
\hline Log-normal & $\mu=(0.0530 \pm 0.0012)$ & -121.5316 & 247.0631 & 247.5640 & 248.3998 \\
& $\sigma=(0.4555 \pm 0.0006)$ & & & & \\
\hline Nakagami & $\mu=(2.2325 \pm 0.0490)$ & -80.2633 & 164.5266 & 165.0274 & 165.8632 \\
& $\omega=(1.5226 \pm 0.0050)$ & & & & \\
\hline Normal & $\mu=\left(1.1374 \pm 0.6792 \times 10^{-3}\right)$ & -64.0309 & 132.0619 & 132.5627 & 133.3985 \\
& $\sigma=\left(0.3477 \pm 0.3477 \times 10^{-3}\right)$ & & & & \\
\hline Rayleigh & $B=(0.8408 \pm 0.0009)$ & -106.8342 & 215.6684 & 215.9188 & 216.3367 \\
\hline Rician & $s=\left(1.0751 \pm 0.8329 \times 10^{-3}\right)$ & -65.3746 & 134.7492 & 135.2500 & 136.0858 \\
& $\sigma=\left(0.3591 \pm 0.4242 \times 10^{-3}\right)$ & & & & \\
\hline \multirow{2}{*}{ Skew-normal } & $\mu=(1.5311 \pm 0.0005)$ & -31.5650 & 69.1300 & 69.8813 & 71.1350 \\
& $\sigma=(0.3212 \pm 0.0003)$ & & & & \\
\hline \multirow{2}{*}{ t-Student } & $\gamma=(-0.9241 \pm 0.0005)$ & & & & \\
& $\mu=(1.1698 \pm 0.0018)$ & -63.6052 & 133.2104 & 133.9616 & 135.2154 \\
& $\sigma=(0.3124 \pm 0.0017)$ & & & & \\
\hline Weibull & $\nu=(10.0589 \pm 137.5842)$ & & & & \\
& $A=(1.2527 \pm 0.0006)$ & -62.8862 & 129.7724 & 130.2733 & 131.1091 \\
& $B=(4.0363 \pm 0.0707)$ & & & & \\
\hline
\end{tabular}

TABLE XV: The results of the statistical modeling of CT for Band C.

\begin{tabular}{|c|c|c|c|c|c|}
\hline Distribution & Parameter estimate & MLE & AIC & BIC & EDC \\
\hline Exponential & $\mu=(1.1039 \pm 0.0068)$ & -195.6078 & 393.2157 & 393.4661 & 393.8840 \\
\hline Gamma & $\begin{array}{l}a=(5.4787 \pm 0.3180) \\
b=(0.2015 \pm 0.0005)\end{array}$ & -107.4669 & 218.9338 & 219.4346 & 220.2704 \\
\hline Inverse Gaussian & $\begin{aligned} \mu & =(1.1039 \pm 0.0022) \\
\lambda & =(3.3797 \pm 0.1283)\end{aligned}$ & -45.4933 & 294.9865 & 295.4874 & 296.3232 \\
\hline Logistic & $\begin{array}{l}\mu=\left(1.1506 \pm 0.8628 \times 10^{-3}\right) \\
\sigma=\left(0.2209 \pm 0.1876 \times 10^{-3}\right)\end{array}$ & -83.9979 & 171.9958 & 172.4967 & 173.3325 \\
\hline Log-logistic & $\begin{array}{l}\mu=(0.0916 \pm 0.0010) \\
\sigma=(0.2507 \pm 0.0003)\end{array}$ & -116.0575 & 236.1149 & 236.6158 & 237.4516 \\
\hline Log-normal & $\begin{array}{l}\mu=(0.0049 \pm 0.0014) \\
\sigma=(0.5041 \pm 0.0007)\end{array}$ & -131.0328 & 266.0655 & 266.5663 & 267.4022 \\
\hline Nakagami & $\begin{aligned} \mu & =(1.8166 \pm 0.0316) \\
\omega & =(1.3629 \pm 0.0057)\end{aligned}$ & -92.9655 & 189.9390 & 190.4318 & 191.2676 \\
\hline Normal & $\begin{array}{l}\mu=\left(1.1039 \pm 0.8141 \times 10^{-3}\right) \\
\sigma=\left(0.3807 \pm 0.4105 \times 10^{-3}\right)\end{array}$ & -80.1585 & 164.3171 & 164.8179 & 165.6538 \\
\hline Rayleigh & $B=(0.8255 \pm 0.0009)$ & -108.8567 & 219.7134 & 219.9638 & 220.3817 \\
\hline Rician & $\begin{array}{l}s=(1.0218 \pm 0.0011) \\
\sigma=(0.3992 \pm 0.0006)\end{array}$ & -81.2115 & 166.4229 & 166.9238 & 167.7596 \\
\hline Skew-normal & $\begin{array}{c}\mu=(1.5492 \pm 0.0006) \\
\sigma=(0.3550 \pm 0.0003) \\
\gamma=(-0.9655 \pm 0.0002)\end{array}$ & -44.4363 & 94.8727 & 95.6239 & 96.8777 \\
\hline t-Student & $\begin{array}{c}\mu=(1.1039 \pm 0.0008) \\
\sigma=(0.3796 \pm 0.0004) \\
\nu=\left(6.2559 \times 10^{6} \pm 7.4749 \times 10^{10}\right)\end{array}$ & -80.1571 & 166.3143 & 167.0655 & 168.3193 \\
\hline Weibull & $\begin{array}{l}A=(1.2267 \pm 0.0008) \\
B=(3.4355 \pm 0.0515)\end{array}$ & -81.1403 & 166.2806 & 166.7814 & 167.6173 \\
\hline
\end{tabular}

